\title{
Disparities in Bulimia Nervosa: Who is Left Behind?
}

\author{
John C. Ham, Daniela Iorio, and Michelle Sovinsky ${ }^{1}$ \\ January 8, 2014
}

(first version February 21, 2011)

\begin{abstract}
Bulimia nervosa (BN) is a serious eating disorder (ED) afflicting a significant number of female teenagers. We compare BN behavior with ED diagnosis among US teenagers using two comparable data samples. We find that African Americans are more likely to exhibit BN behavior than Whites, as are girls from low income families. However, Whites are much more likely to be diagnosed with an ED, indicating important racial and class differences in medical attention for BN. Thus greater outreach must be made in terms of diagnosing and treating BN among African American and low income teenage girls.

Keywords: Bulimia Nervosa, Race, Income, Education

JEL Codes: I1

\footnotetext{
${ }^{1}$ Ham is at the University of Maryland, IFAU, IFS, IRP (Madison), and IZA. Iorio is at Universitat Autonoma de Barcelona and Barcelona GSE. Sovinsky is at the University of Zurich and CEPR. Corresponding author is Sovinsky (email: michelle.sovinsky@gmail.com). The authors thank Lynne Casper, James Heckman, Geert Ridder, Seth Sanders, Duncan Thomas for helpful comments. They are grateful to the National Science Foundation, the Swiss National Science Foundation (S-33125-01-01), the Claremont McKenna Lowe Institute for Political Economy, the USC College of Letters, Arts and Sciences, the Ministerio de Educacion y Ciencia (SEJ2006-00712), Ministerio de Ciencia y Tecnologia (SEJ2006-00538), the Barcelona GSE, and the government of Catalonia for financial support. Any opinions in this paper are those of the authors and do not necessarily reflect the views of the NSF.
} 


\section{Introduction}

Eating disorders (ED) are an important and growing health concern in the United States, where 20 million women suffer from a clinically significant eating disorder at some time in their life. One form of eating disordered behavior is bulimia nervosa $(\mathrm{BN})$, which is characterized by bingeing and purging. The prevalence of $\mathrm{BN}$ in the population is unclear as it is not always diagnosed. $^{2}$ Moreover, the seriousness of BN is accentuated by the fact that only about half of the patients diagnosed with BN fully recover (Keel et al., 2005). Further, the problem may be growing since BN cases are occurring at ever younger ages. Traditionally the age of onset on BN has been between 14 and 25 years, but the behavior is increasingly seen in children as young as 10 (Cavanaugh and Ray, 1999).

While there has been increasing research focusing on health disparities by race and class (Adler and Rehkopf, 2008), investigations concerning the incidence of BN or EDs across socioeconomic groups remains scarce, even though the impact on health of EDs is significant especially given the early age of onset. As reported by the National Eating Disorder Association, "exact statistics on the prevalence of EDs among women of color are unavailable. This may be due to our historically biased view that EDs only affect white women, and relatively little research has been conducted utilizing participants from racial and ethnic minority groups." 3

The contribution of this study is twofold. First, it offers a fresh view of the distribution of bulimic behavior across socioeconomic groups that runs counter to conventional wisdom, and is policy relevant, as it suggests that greater outreach for BN should be made to African Americans and to individuals from low income families. Second, it raises a flag against conducting future research on a sample solely drawn from diagnosis, as the results may not be applicable to a larger population and may contribute to reinforce the misleading picture of mixing who is at major risk versus who is more likely to be referred to or seek out ED treatment.

We analyze data from two datasets. The first is the National Heart, Lung, and Blood Institute Growth and Health Study (henceforth NHLBIS), which is a panel data set on female adolescents' behaviors. A notable aspect of the NHLBIS is that all respondents were asked a large number of questions related to bulimic behavior, independent of any diagnoses or treatment they had received. The survey questions were designed by a panel of medical experts

2 However, over the past decade 6 to $8.4 \%$ of female adolescents reported purging to lose weight (National Youth Risk Behavior Survey, 2005). Across studies of White women, the lifetime prevalence of AN and BN is between $0.9-1.6$ and $1.5-2.8$ respectively. The figures for males are 0.3 and $0.5 \%$ respectively. See Wade, et al. (2011) and references therein.

3 Quote taken from http://www.nationaleatingdisorders.org/eating-disorders-women-color-explanationsand-implications. Last asccess Oct 31, 2013. 
to assess the psychological characteristics and symptoms that are relevant to detect bulimic behavior (Garner et al., 1983). Based on the answers to these questions, they constructed an Eating Disorders Inventory-BN scale, which is widely used in ED research. This stands in contrast to many data sets, where often a measure of ED or BN behavior is available only if the respondent had been diagnosed with, or was being treated for, an eating disorder.

Our results reveal that African-American girls report a stronger tendency towards bulimic behavior than do White girls. For example, being White lowers the Eating Disorders InventoryBN scale by $20 \%$ relative to its mean value. Further, our results reveal interesting BN patterns across family income groups. For example, the poorest girls exhibit a $32 \%$ increase of symptoms of bulimia (relative to the mean of the Eating Disorders Inventory-BN scale) when compared to middle class girls, and a $40 \%$ increase when compared to wealthier peers. Regarding the race-income interactions, low and middle income African American girls, and low income White girls, are at substantially higher risk of BN behavior than girls from other race-income groups.

However, if individuals from certain income or racial groups are more likely to seek treatment, results based on data from diagnosed individuals can present a very misleading picture of the incidence of EDs across SES groups. To investigate the impact of selection on ED treatment, we use a well-known dataset, the National Longitudinal Study of Adolescent Health (hence-forth Add Health), where we only know a girl has eating disordered behavior if she is diagnosed. Using these data, we find that White girls in a high income household with highly educated parents are almost twice as likely to be diagnosed (5.9\%) relative to an average girl. In contrast, only $0.7 \%$ of African American girls in low-income households have been diagnosed with an ED. Our results show that the popular conception that EDs are important primarily for White upper income girls is consistent only with who is diagnosed with an ED, suggesting dramatic differences in diagnosis across race and income classes. These findings corroborate our hypothesis that ethnic minority and disadvantaged groups are significantly less likely to receive or seek out care for EDs, despite the fact that these are the groups more at risk. Before turning to the next section, three final considerations are in order.

First, based on the observation that people with ED tend to share similar personality and behavioral traits, including low self-esteem and being a perfectionist, we add personality traits (such as perfectionism tendencies, feelings of ineffectiveness and distrust) to our outcome equations. Using such psychological measures has been useful in describing race and class differences in health disparities in general, and a relationship between these measures and BN is discussed in the medical literature. The best-known contributor to the development of EDs is body dissatisfaction: $40-60 \%$ of elementary school girls (ages 6-12) are concerned about 
their weight or shape. ${ }^{4} \quad$ As Adler and Rehkopf (2008) stress, these factors may diminish the role of race and class in health outcomes simply because the personality traits are being driven by race and class. (For example, stress is an important factor in many diseases, but it may be a result of the barriers that non-white, low income individuals face.) Interestingly, when we add personality traits we find that they are significant determinants of BN behavior, but our significant results for race and class continue to hold. In fact the results for the SES variables become somewhat stronger, suggesting that outreach be based on both the SES characteristics and the personality traits. Finally, since we have repeated observations on the personality characteristics and BN behavior, we ask whether the personality traits continue to be important once we estimate a fixed effect model, as this would cast doubt on the hypothesis in the medical literature that a single factor is driving both the personality traits and $\mathrm{BN}$ behavior. We do indeed find that the personality traits continue to be significant determinants of $\mathrm{BN}$ behavior once we include fixed effects.

Second, it is worth spending a word on the issues of selection and reverse causation, which are particularly serious problems in the disparity literature (e.g., individuals have low income because of their health problems), as noted by Adler and Rehkopf (2008). Since NHLBIS is a stratified random sample, selection is not an issue with these data. Moreover, the income measures we use are those of the teens' parents, so reverse causality also is not a problem in this study. Finally, racial differences in health outcomes may be a result of race-specific genetic factors (as with sickle cell anemia, for example). However, since the effect of race in our analysis differs across class, e.g., high income Whites and African Americans are at low risk of BN in our data, this does not seem like a relevant concern.

Third, the NHLBIS is not a representative sample because it is stratified by race and income, and is drawn from three US urban areas: Richmond, CA; Cincinnati, OH; and Seattle, Washington. If there are heterogeneous treatment effects, the stratification strategy behind the NHLBIS will, by itself, lead to differences between the NHLBIS and Add Health results. To investigate this issue for the stratification by race, income and living in an urban area, we conduct robustness checks using different subsamples of the nationally representative Add Health data to mimic this NHLBIS stratification. Our results show no evidence that differences in the NHLBIS and Add Health results are being driven by differences in stratification by income, race or urban status. Moreover it is important to remember that the race/income stratification strategy in NHLBIS makes it much easier to distinguish between race and income effects. However, we cannot rule out that our results reflect differences between teenage girls

${ }^{4}$ All the statistics mentioned above are obtained from a report of the National Eating Disorder Association, (NEDA 2012). 
from these three cities and the rest of the country. However, since our results are extremely suggestive of race and class differences in the diagnosis of a serious disease, they should be taken quite seriously and certainly motivate the need for additional data collection and study.

The outline of the paper is as follows. In section 2 we present a brief review of the literature. In section 3 we describe the data and present basic statistics on the incidence of $\mathrm{BN}$. We examine the role played by selection in the disparities in $\mathrm{BN}$ incidence in section 4 . In section 5 we present the results regarding the predictive role of socioeconomic status in the incidence and intensity of bulimic behaviors. These results are policy relevant as they provide insight into which girls are at the greatest risk for $\mathrm{BN}$ and thus guide the direction of future outreach. In section 6 we present results controlling for personality characteristics as a way of understanding the racial and class differences. We conclude in section 7 .

\section{Literature Review and Background}

The primary characteristic of $\mathrm{BN}$ is the recurrent episodes of binge-eating followed by compensatory behavior, which includes self-induced vomiting, misuse of laxatives, diuretics, or other medications, fasting, or excessive exercise. The bingeing and purging cycle usually repeats several times a week, and as a result, BN can be extremely harmful to the body and cause serious health problems. For example, the cycle of bingeing and purging can lead to electrolyte and chemical imbalances that affect the heart (i.e., irregular heartbeats and possibly heart failure). Other health concerns include the inflammation of the esophagus, gastric rupture, tooth decay, muscle weakness, and anemia (American Psychiatric Association, 1993). The negative impact of $\mathrm{BN}$ is even more serious for the very young since $\mathrm{BN}$ has irreversible effects on physical development and emotional growth. ${ }^{5}$ Moreover, bulimics persist in their behaviors (Keel, et al., 2005; Ham, Iorio, and Sovinsky, 2013). Hence, as with any serious persistent disease, BN is likely to negatively affect human capital accumulation as it will cause students to miss class and to be less attentive in class. It may also reduce on-the-job training if it prevents individuals from holding stable employment for demanding jobs. In addition, there are other costs of BN including days lost from work. Thus BN can impose serious costs to the economy in terms of physical health, treatment costs, increased absence from work, and reduced human capital accumulation.

Given the number of people affected and the seriousness of the effects, BN should be thought of as a primary health issue. However, public campaigns targeting BN remain scarce, as noted by

\footnotetext{
5 The harmful side effects consist of pubertal delay or arrest and impaired acquisition of peak bone mass resulting in growth retardation and increased risk of osteoporosis (Society for Adolescent Medicine, 2003).
} 
the Senate Committee of Appropriations, who expressed concern about the "growing incidence and health consequences of eating disorders among the population" (Department of Health and Human Services, 2006). ${ }^{6}$ In contrast, there is a major push to reduce obesity, and this comes at a cost that receives little or no attention: campaigns fighting obesity could move individuals who are currently bingeing on food to engage in both bingeing and purging behaviors leading to all the negative consequences that arise from BN. ${ }^{7}$ Thus policy aimed at BN has an important role to play. However, implementation is difficult given how little is known about the disorder, as realized by the Senate Committee that emphasized the need for research on the incidence of EDs across demographic groups. For example, popular culture portrays EDs as affecting relatively affluent White women who are highly educated, or come from high income families ${ }^{8}$ but, to our knowledge, there is no multivariate analysis to confirm or deny this assertion. ${ }^{9}$ Thus it is not clear whom should be targeted by health campaigns.

In 2006 the Agency for Healthcare Research and Quality (Department of Health and Human Services, 2006) published a comprehensive review of papers on ED published in the epidemiology literature since 1980. As the report notes, these studies are mainly focused on the effectiveness of different treatment programs. More recent epidemiological studies (Alegria, et al., 2007; Nicdao, et al., 2007; and Taylor, et al., 2007) have used surveys focused on minority racial groups to examine univariate correlations in ED behaviors and racial groups. These papers did not find evidence that race influences the development of eating pathology. However, the BN diagnostic criteria used in these papers, the Composite International Diagnostic Interview, has only one question related to bingeing behaviors and no questions related to purging so it is not ideal for examining $\mathrm{BN}$ behavior.

Hudson et al. (2007) document the prevalence of various types of ED behaviors among women and men (in a univariate framework) using data from the National Comorbidity Survey Replication. Reagan and Hersch (2005) investigate the frequency of bingeing behavior (but not

6 According to the 2004 School Health Profiles study, only 25 states had a least one school that taught students about EDs. The percent of schools providing ED education in these states ranged from 78 to 99 , where the majority of ED programs were in high schools.

7 For example, in preliminary regressions using data from the National Longitudinal Study of Adolescent Health we found that women who have been exposed to preventative educational programs on the dangers of being overweight report more severe bulimic behaviors. These concerns have also been raised in a number of publications in the ED literature and more recently the Academy for Eating Disorders commented on the risk of unintended negative consequences from obesity education (see Danielsdottir et al., 2009).

8 See Kempa and Thomas (2007) and references therein.

9 The epidemiological literature that estimated the incidence of BN across racial or income groups often suffers from at least one of the following: i) focuses on univariate correlations, ii) creates a selection problem by only considering those diagnosed with an eating disorder, or iii) does not distinguish between correlations and causal factors. See the related literature section for a further discussion. 
purging) using cross-sectional data from the Detroit metropolitan area. They find that there are no race or age effects on bingeing behavior (holding constant gender and obesity status), and that marital status, neighborhood, and income play a role among women. Compared to Reagan and Hersch (2005), we focus on BN and not just purging. Secondly we do not condition on neighborhood effects, since a family's neighborhood can be determined primarily by their race and income. We also do not condition on obesity since it is obviously jointly determined with BN behavior. We also have somewhat wider geographic variation than Reagan and Hersch. Finally we examine the role of personality characteristics in explaining race and class differences in $\mathrm{BN}$.

A related epidemiological study using the NHLBIS is Striegel-Moore et al. (2000), who examine univariate correlations between $\mathrm{BN}$ and race and between BN and parental education. Their univariate results show that BN is higher among African Americans girls. They only condition on race, but as Adler and Rehkopf (2008) note, this is likely to bias the effect of race if there are important race-income interactions that determine $\mathrm{BN} .{ }^{10}$

Interesting we find that these racial differences remain when we also control for the family income and indeed find interesting race-income interactions in determining BN behavior. Specifically, we find that low and middle income African American girls, and low income White girls, are at substantially higher risk of BN behavior than girls from other race-income groups. Below we show that these racial differences remain when we also control for the education of the parent, family income and personality characteristics. However, we find a more subtle pattern when we interact income class and race: low and middle income African American girls, and low income White girls, are at substantially higher risk of BN behavior than girls from other race-income groups. Our work differs from all these papers because we use an additional dataset to investigate whether the race-social class disparities in bulimic behavior are consistent across samples (girls who could be potentially at risk for EDs versus girls that have been diagnosed with EDs) and highlight how sample selection can lead to a misleading picture about the SES groups that are more at risk.

The importance of our results for policy is reinforced by our finding in other work (Ham, Iorio, and Sovinsky, 2013) that up to two-thirds of the persistence in BN is due to state dependence, which suggests that early interventions in terms of treatment may be very beneficial. In other words, there are significant class and race disparities for a disease where remaining untreated will magnify the severity of the disease.

This paper is related to the literature examining disparities in health outcomes by income,

${ }^{10}$ Given the stratified sampling used to collect the NHLBIS, race and income are orthogonal in the data, so simply omitting income will not bias the results. 
race, and education (see e.g., Currie and Hyson, 1999; Khanam et al., 2009, Smith, 2007; Tenn et al., 2010, Thompson, 2011), but none of these papers examine differences in incidence and treatment. A number of empirical papers also document differences in education and socioeconomic status for the prevalence of obesity (Cutler et al., 2003; Philipson and Posner, 2008; Kemptner et al., 2011); again these papers do not investigate possible differences in treatment and incidence for obesity. Also, note that while these papers and ours are related in the broad sense of pertaining to food consumption, obesity and BN are very different conditions, since, e.g. women suffering from BN are characterized by average body weight (Department of Health and Human Services, 2006). Finally, our work is tangentially related to the issue of differences across race and class of poor child health and nutrition, which can reduce both the time spent in school and the learning process during that time. However, note again this literature does not usually distinguish between the incidence of these conditions and their treatment (Glewwe and Miguel, 2008 and references therein).

\section{Data Description}

We use the NHLBIS to investigate the incidence of $\mathrm{BN}$ behavior by race and income class, while to study diagnosis we use the Longitudinal Study of Adolescent Health data (hereafter Add Health). We now describe each dataset in turn.

\subsection{The National Heart, Lung, and Blood Institute Growth and Health Study}

The NHLBIS includes girls from schools in Richmond, California and in Cincinnati, Ohio, as well as from families enrolled in a health maintenance organization in the Washington, DC area. $^{11}$ The survey was conducted annually for ten years, and starting in 1990, when the girls were aged 11-12, the survey contains questions on BN behavior that were asked approximately every other year. ${ }^{12}$ It contains substantial demographic and socioeconomic information such as age, race, parental education, and initial family income (in categories). The data also contain a number of time-varying psychological or personality indices (reflecting the potential

\footnotetext{
11 Due to confidentiality concerns, the data do not indicate where an individual lives. Selection of potential schools was based on census tract data that showed approximately equal fractions of African American and White children, and the least disparity in income and education between the respondents of the two ethnic groups. The majority of the cohort, selected via the Health Maintenance Organization (HMO), was randomly drawn from a membership list of potentially eligible families with nine (or ten) year-old girls. A small percentage was recruited from a Girl Scout troop located in the same geographical area as the HMO population.
}

12 The attrition rate after ten years was $11 \%$. 
for personality disorders).

The NHLBIS was constructed to have equal numbers of African Americans and Whites, and to have approximately equal representation across different income groups for African Americans and Whites (Kimm et al., 2002). The use of exogenous stratification is particularly useful for examining the role that race and income play in the incidence of BN. For example, a nationally representative sample would have to be much larger than NHLBIS to obtain equivalent numbers of high and middle income African Americans; alternatively, a random sample of the same size would have little power to examine the differences across races-income cells. ${ }^{13}$ Furthermore, if the equations we estimate are constant across individuals, we will obtain consistent estimates of the national parameters (except for the constant) that are comparable to the coefficients determining who receives treatment. However, if coefficients are heterogeneous across individuals, then we need to reweight to obtain comparable coefficients across the two samples, and we investigate that below.

To the best of our knowledge the NHLBIS has not been used previously in economics by other authors, so we now describe the data and variable construction in some detail. The data consist of ten waves of 2198 girls, where questions on BN behavior were asked in waves 3, 5, 7,9 , and 10. The questions were formulated to be consistent with diagnostic criteria for BN and were adjusted to be easy to understand for young respondents. ${ }^{14}$ The survey contains an Eating Disorders Inventory-BN scale for each respondent (hereafter the ED-BN index), which measures degrees of the symptoms associated with BN. The ED-BN index is constructed based on the subjects responses ("always" $=1$, "usually" $=2$, "often" $=3$, "sometimes" $=4$, "rarely" $=5$, and "never" =6) to seven items: 1) I eat when I am upset; 2) I stuff myself with food; 3) I have gone on eating binges where I felt that I could not stop; 4) I think about bingeing (overeating); 5) I eat moderately in front of others and stuff myself when they are gone; 6) I have the thought of trying to vomit in order to lose weight, and 7) I eat or drink in secrecy. A response of 4-6 on a given question contributes zero points to the ED-BN index; a response of 3 contributes 1 point; a response of 2 contributes 2 points; and a response of 1 contributes 3 points. The ED-BN index is the sum of the contributing points and ranges from 0 to 21 in our data. For instance, if a respondent answers "sometimes" to all questions, her ED-BN index will be zero. ${ }^{15}$

13 These sort of issues motivate the National Longitudinal Survey oversampling of African Americans (and Hispanics) and the Panel Study of Income Dynamics oversampling of low income families. See Chapter 7 of the BLS Handbook of Methods on the National Longitudinal Survey and Chapter 5 of the PSID User Guide.

14 Clinical criteria for BN, according to the Diagnostic and Statistical Manual of Mental Disorders fourth edition (American Psychiatric Assocation, 2000), require the cycle of binge-eating and compensatory behaviors occur at least two times a week for three months or more and that the individual feel a lack of control during the eating episodes. Due to data restrictions, we cannot examine the prevalence of anorexia nervosa. 
Therefore, a higher ED-BN score is indicative of more intense BN behavior.

The ED-BN scale is widely used in ED research (Rush et al., 2008). According to the panel of medical experts that designed the index (Garner et al., 1983), a score higher than 10 indicates that the girl is very likely to have a clinical case of BN. In order to externally validate the ED-BN index, a sample of women diagnosed with BN (according to the Diagnostic and Statistical Manual of Mental Disorders (DSM-IV) criteria) was interviewed using the NHLBIS questionnaire: the average ED-BN index among this sample was 10.8. ${ }^{16}$ Approximately $2.2 \%$ of the respondents scored higher than 10 in the NHLBIS sample, which is close to the national average of clinical BN reported from other sources. ${ }^{17}$ Based on these considerations, we refer to a respondent with a score of the ED-BN index greater than 10 as one exhibiting bulimia nervosa.

\section{$<$ Insert Table 1 here $>$}

A team of medical experts designed additional questions to construct four indices that measure a respondent's potential for personality traits/disorders (henceforth, "personality indices"), which are likely to be associated with BN. ${ }^{18}$ The first index assesses how much the respondent is dissatisfied with the size and shape of specific parts of her body, and hereafter we refer to this index as the body dissatisfaction index. The remaining three personality indices assess tendencies toward: perfectionism (hereafter the perfectionism index), feelings of ineffectiveness (hereafter the ineffectiveness index), and interpersonal distrust (hereafter the distrust index). For all the personality indices, a higher score indicates a higher tendency of the personality trait that the index quantifies. For ease of exposition, we provide details on the questions used to form the personality indices in Appendix A.

We report variable means, standard deviations, and the standard errors for the mean values of the NHLBIS sample in Table 1. For all demographic variables except age we have one observation per person, while for the other variables we have multiple observations per person; we adjust the standard errors of the mean to take this into account. ${ }^{19}$ The mean of the ED-BN index is 1.2, and the average age of the girls over the sample is approximately 14 years. As noted above, by design, individuals in the sample are approximately equally distributed across

\footnotetext{
15 Note that the answers to the individual questions are not available in the data.

16 See Garner et al. (1983) for more details of the development and validation of the ED-BN index.

17 See for instance, Hudson et al. (2007) and National Eating Disorders Association (2008).

18 See Garner et al., 1983 for a discussion of the association of these personality characteristics with EDs.

19 Given that parent's education and race are very unlikely to change, except perhaps by remarriage, the only SES variable for which it would be interesting to have multiple observations is family income.
} 
race and income. Further, given the high correlation between income and education, it is not surprising that the girls are approximately equally distributed across parent's education levels.

\section{$<$ Insert Table 2 here $>$}

Table 2 illustrates the relationship between the demographic variables and the ED-BN index. For a given demographic group, we present the percentage of young women with an ED-BN index of zero, in the range [1-5], [6-10] and greater than 10 (i.e., bulimia nervosa), in columns (1)-(4), respectively; thus each row adds up to 100. Immediately one sees that the popular conception that $\mathrm{BN}$ is a disorder that afflicts upper income class White girls is contradicted. For example, an ED-BN index equal to zero is more prevalent among Whites than African-Americans, but the reverse occurs for a positive ED-BN index.

One could be concerned that these findings are due to an incorrect interpretation of what the ED-BN index measures, i.e., the possibility that it might capture obesity instead of bulimic behaviors. However, this concern is invalid for the following reasons. First, if the index was actually measuring obesity, we would expect a strong positive correlation between ED-BN scores and body mass index (BMI), while the correlation in the data for all girls is only 0.05 , and is actually negative for African Americans. Second, one might be concerned that this correlation is driven by the highest values of the ED-BN scores, and that the index represents obesity among those scoring 0-10. However, average BMI for girls with an ED-BN index above 5 (i.e., the midpoint of the $0-10$ interval) is lower than average BMI for girls with an index of 5 or lower for both African Americans (22.48 versus 24.72) and Whites (20.55 versus 22.14). These statistics strongly suggest that the ED-BN index is not an obesity index.

Note also that there is a monotonic relationship between the SES variables (family income, parents' education and race) and the ED-BN index in all brackets of the ED-BN index. Combined with the results for African Americans, Table 2 suggests that BN is more problematic among African American girls, girls from low income families, and girls from families with low parental education. One possibility is that the results for race or class will disappear once we condition on both variables, but this is unlikely since income and race are uncorrelated by the sample design. However a multi-variate analysis will also allow for a full set of interactions to give us a richer understanding of the incidence of $\mathrm{BN}$, and we find that the race and class differences persist when we do this. Once we establish these disparities, we then ask whether they are being driven by differences in the personality indices given the emphasis in the medical literature on the link between BN and the indices. ${ }^{20}$ This Table illustrates that simply

\footnotetext{
${ }^{20}$ Indeed we see evidence of this possibility in the raw data, since the univariate correlations between each of the personality indices with both the ED-BN index and the incidence of clinical BN are positive, ranging
} 
aggregating the ED-BN index into an incidence of BN, i.e., column (4), would discard valuable information about the distribution of severity of bulimic symptomatology across SES groups. Indeed our results presented in section 5 show that coefficients are of the same sign when we analyze the ED-BN index and the incidence of bulimia nervosa, but the former are much more precisely estimated.

\subsection{The Longitudinal Study of Adolescent Health}

The Add Health survey is a longitudinal data set that examines health-related behaviors of adolescents who were in grades 7 through 12 in 1995. ${ }^{21}$ It is a school-based, stratified, random sample of all high schools in the U.S. in 1995. ${ }^{22}$ The data were collected from students, parents, siblings, fellow student peers, and school administrators, and include social and demographic characteristics of respondents and self-reported bingeing and purging behaviors. In addition, in 2002 (wave 3) the respondents were asked the following question: "Have you ever been told by a doctor that you have an eating disorder, such as anorexia nervosa or bulimia?" This is the variable we use to detect the girls that have been diagnosed with an ED. Note that, while we cannot separately identify bulimic and anorexic patients, we have reasons to believe that this variable detects a higher number of bulimic cases since according to the statistics gathered by epidemiologists: the incidence of $\mathrm{BN}$ is twice as large as the incidence of $\mathrm{AN}$; a large percentage of individuals may have both eating disorders at the same time, and it has been estimated that about $50 \%$ of anorexic patients develop BN or bulimic patterns and that $30 \%$ to $40 \%$ of bulimics will develop AN. ${ }^{23}$ Information about parental income and education were collected in 1995, and we constructed variables on family income to match the ones in the NHLBIS, so that the two data sets have similarly defined SES groups. Specifically, we replicated the NHLBIS income brackets (in 1988 constant dollars). Since parental education

from 0.22 to 0.44 and 0.11 to 0.27 respectively, and all of these correlations are statistically significant at the $1 \%$ level.

21 This research uses data from Add Health, a program project directed by Kathleen Mullan Harris and designed by J. Richard Udry, Peter S. Bearman, and Kathleen Mullan Harris at the University of North Carolina at Chapel Hill, and funded by grant P01-HD31921 from the Eunice Kennedy Shriver National Institute of Child Health and Human Development, with cooperative funding from 23 other federal agencies and foundations. Special acknowledgement is due Ronald R. Rindfuss and Barbara Entwisle for assistance in the original design. Information on how to obtain the Add Health data files is available on the Add Health website (http://www.cpc.unc.edu/addhealth). No direct support was received from grant P01-HD31921 for this analysis.

${ }^{22}$ A school was eligible if it included an 11th grade and had a minimum enrollment of 30 students. Feeder schools, those that sent graduates to the high school and that included a 7th grade, were also included.

${ }^{23}$ See Wade, et al. (2011), and the National Association of Anorexia Nervosa and Associated Disorders, Inc. website. Accessed Oct. 2013. http://www.anad.org/get-information/about-eating-disorders/eating-disordersstatistics/ 
is coded in a similar fashion in both datasets, we did not adjust the Add Health education variable. Further, to make meaningful comparisons across the two datasets, we only considered female, African-Americans and Whites in the Add Health data, and we refer to the resulting data set as the Add Health BW. When we further restricted our attention to urban residents in the Add Health data, we refer to this subsample as the Add Health BWU. Table 3 reports the variable means and standard deviations of our Add Health BW and Add Health BWU samples for wave 3 (the only wave that contains information on diagnosis).

$<$ Insert Table 3 here $>$

The Add Health BW and Add Health BWU samples are very similar. As Table 3 indicates individuals in the Add Health BW and BWU samples are on average 20 years of age, with an ED incidence of about 3.5\%. The diagnosed sample is slightly younger, and contains a larger percentage of White girls. Parental education is similar across datasets where girls that have been diagnosed with an ED are more likely to have higher educated parents from a higher income category.

\section{Disparities in the Incidence of BN: Selection into Treat- ment}

In this section we show that our findings challenge the belief that BN primarily affects affluent White teenagers. An interesting question is why does this divergence between our results and popular conceptions occur? We believe one potential explanation is that popular opinion appears to be based on who has been diagnosed with an eating disorder, and not the potentially different group of those who exhibit bulimic behaviors. To investigate this conjecture we compare the estimates of the SES gradient using data from the Add Health survey, which contains information on who is diagnosed with an ED, and from the NHLBIS study, which contains information on $\mathrm{BN}$ behavior but not on ED diagnosis. Having data on those who seek treatment versus those who are potentially at risk is necessary to examine whether the estimates of the SES-BN incidence gradient are biased if certain groups are much more likely to seek medical attention for BN.

While we have a continuous ED-BN measure, only 0-1 information on ED diagnosis is available from Add Health. Thus for comparability we estimate a probit model on both data sets, defining the outcome variable for the NHLBIS (denoted $y_{i t}$ ) as 1 if the ED-BN index is greater than 10 and 0 otherwise. The outcome variable for the Add Health (denoted $y_{i}^{A d d}$ ) is equal to 1 if the individual has been diagnosed with an ED and 0 otherwise. 
We construct regressors that are consistent across the data sets. The probit model using the Add Health sample is

$$
y_{i}^{A d d *}=\alpha_{0}+\alpha_{1} X_{i}+\alpha_{2} A_{i}+e_{i}
$$

The vector $X_{i}$ represents the SES variables while $A_{i}$ denotes age; we assume the $e_{i}$ are i.i.d $N\left(0, \sigma_{e}^{2}\right)$. The observed outcome variable is determined by

$$
y_{i}^{A d d}=\left\{\begin{array}{c}
0 \text { if } y_{i}^{A d d *} \leq 0 \\
1 \text { otherwise. }
\end{array}\right.
$$

Since NHLBIS is a panel we write the index function as

$$
y_{i t}^{*}=\alpha_{0}+\alpha_{1} X_{i}+\alpha_{2} A_{i t}+u_{i}+e_{i t}
$$

where $u_{i}$ is a random effect. We assume the error terms $u_{i}$ and $e_{i t}$ are independent from one another and distributed i.i.d $N\left(0, \sigma_{u}^{2}\right)$ and $N\left(0, \sigma_{e}^{2}\right)$ respectively. The observed outcome variable is determined by

$$
y_{i t}=\left\{\begin{array}{c}
0 \text { if } y_{i t}^{*} \leq 0 \\
1 \text { otherwise. }
\end{array}\right.
$$

For the NHLBIS we estimate the model by forming a quasi-likelihood of the period by period observations and cluster the standard errors by individual. We also adopt a similar procedure when we estimate the Tobit and Ordered Probit models below.

\subsection{Results: Who is Left Behind?}

Table 4 presents the Probit partial effects when using the two data sources mentioned above. Columns (1) - (5) provide the results obtained with the NHLBIS, which is based solely on behavior. $^{24}$ As shown in column (1), the propensity of being bulimic is nearly 19 percentage points lower among White girls than among African-American girls holding parents' education constant. In other words, Whites have, on average, an $88 \%$ smaller chance of exhibiting bulimic

\footnotetext{
${ }^{24}$ We believe a self-reported questionnaire used to evaluate the presence and severity of bulimic symptomatology can be considered objective in the sense that girls are not asked if they have an ED, but rather are asked a series of questions about their behavior. Any diagnosis of BN, or any disease with a behavioral component, is based on more detailed versions of these questions. In other words, we are using a limited version of the information a physician would use to determine whether to make a diagnosis.
} 
behavior (the mean value of bulimia is $2.2 \%$ in the NHLBIS). Column (1) shows that, holding race constant compared to those families where none of the parents attended college, when at least one parent started college, the daughter is about 25 percentage points less likely to engage in bulimic behavior, and when at least one parent completed college (or higher degree), the percentage points further drop to 37. To place these numbers in perspective, moving from the lowest to the highest parents' education category decreases the probability of exhibiting bulimic behavior by more than half holding race constant. When we allow for an interaction between race and parental education (see column (2)), there is no significant difference between African Americans and Whites when the parents are high school graduates. Also, having at least one parent who started college decreases the probability of showing bulimic behavior in both racial groups, and (in absolute value) it is $27 \%$ higher for Whites $(0.37 / 0.22$ versus $0.29 / 0.22$, the former is 1.27 times larger than the latter). Finally, when comparing the educational disparity between the highest educated (White or African American) group and the base group, the drop in the probability of exhibiting bulimic behavior is more pronounced for Whites $(0.614 / 0.22$ versus $0.285 / 0.22$, the former is 2.15 times larger). In columns (3) and (4) we examine the role played by family income. The probability of exhibiting bulimic behavior decreases in family income, and the size of the income disparities is remarkably high. For example, when compared to the base group, coming from the highest income category halves the probability of being bulimic (column (3)). This difference is even stronger when we consider Whites and African Americans separately (see column (4)). In column (5) we include both income and education, and the results yield similar patterns.

\section{$<$ Insert Table 4 here $>$}

In the remainder of Table 4 we have placed the results for diagnosis using the Add Health data. In contrast to the NHLBIS estimates, the Add Health estimates reveal that White teenagers are more likely to be diagnosed with an ED. In order to obtain estimates from the Add Health that are comparable to the NHLBIS, we restrict our attention to the Add Health BWU sample in columns (6)-(10). Approximately 3.4\% of the girls in the Add Health BWU data have been diagnosed with an ED. However, White girls are around $3 \%$ points more likely to be diagnosed with an ED than African Americans (that is, they have on average almost a $100 \%$ higher chance of being diagnosed) when holding parent's education constant (column 6) or holding income constant (column 8). ${ }^{25}$ One might be concerned that, given the geographical restriction of the NHLBIS sample (i.e., only urban girls) and its race/income stratification, our

\footnotetext{
${ }^{25}$ Unfortunately for some SES groups in the Add Health data, we have too little variation in the ED variable to obtain significant estimates of the interaction effects.
} 
results may not hold when we consider a larger population (i.e., the Add Health BW sample). However, the estimates we obtain pooling urban and not urban samples (column 11) are very similar to the ones obtained using only the urban sample (column 10). Column (12) reports the weighted least squares estimates for the BWU sample, where the weights are proportional to the relative NHLBIS size of each ethnic/income group so as to mimic the stratification by income and race adopted in the NHLBIS. That is, using these weights, the relative Add Health BWU sample size of a given SES group corresponds to the relative NHLBIS size of the same SES group. We do not observe any remarkable difference in the unweighted estimates obtained in the representative sample, suggesting heterogenous treatment effects is not an issue. These robustness checks reveal that it is unlikely to observe geographic variation in the ED prevalence, or in its racial/income patterns, and reassure us that the lack of geographic representativeness in the NHLBIS is unlikely to affect the comparability of the parameter estimates across data sets due to parameter heterogeneity. ${ }^{26}$

In sum, our results corroborate our conjecture that there is a selection bias if we simply select on whether a girl is diagnosed with an ED. Our findings are policy relevant as they allow policy-makers to target resources towards groups that are most likely to be affected by $\mathrm{BN}{ }^{27}$ We next turn our attention to better understand the racial/income patterns.

Recall that in the NHLBIS data we do not know whether the girl has been treated for BN, so the estimated coefficients for racial/income differences in the incidence of BN may reflect both different propensity to engage in bulimic behavior across socioeconomic groups, as well as racial/income differences in treatment; given our Add Health results, one might expect that girls from White and/or high income families in the NHLBIS are more likely to receive treatment that mitigates bulimic behavior over time. Our data allow us to shed some light on this issue. Recall that the survey starts when girls are younger than the average onset age for BN (e.g., 1112 years old in wave 3), hence, it is likely that those exhibiting bulimic behavior just started and have not yet been diagnosed or treated. Thus if we use only data from wave 3, the ED-BN index should mainly reflect only differences in the propensity of engaging in $\mathrm{BN}$, and not the potential racial/income differences in treatment. When we estimate a regression model with the ED-BN index as dependent variable using data from wave 3 (as we detail in the next section), we find that the difference in incidence between Whites and African Americans is even higher (and still statistically significant) than what we obtained by pooling all waves. Being White now lowers

\footnotetext{
${ }^{26}$ Recall that reweighting should not affect the parameter estimates unless there is parameter heterogeneity; indeed this idea places an important role in the tests suggest by Hausman (1978).

27 These results are consistent with contemporaneous studies in the medical literature providing anectdotal evidence of ethnic disparities in utilization of eating disorders care. See Becker et al. (2010) and references therein.
} 
the ED-BN index by 0.65. Similarly, as compared to the lowest income group, being middle (high) income lowers the index by about 0.42 (0.48), and these differences also are statistically significant. Overall, these findings suggest that there are remarkable racial/income differences in the propensity towards engaging in bulimic behavior. However, it is important to note that irrespective of how one interprets our results, the implication is that there is a large untreated group (e.g., African Americans and girls from low-income families) at whom outreach should be aimed.

\section{$5 \quad$ Understanding the SES-BN Gradient for those at Risk}

For comparability with the Add Health results, our analysis above for the NHLBIS data only exploits the difference between girls with a BN-ED greater than 10 in a given period to girls with a BN-ED less than or equal to 10. Since we have a continuous ED-BN index, considering only a 0-1 outcome potentially wastes a lot of variation in the ED-BN index. To exploit this variation we consider the regression

$$
d_{i t}=\beta_{0}+\beta_{1} X_{i}+\beta_{2} A_{i t}+\gamma_{i}+v_{i t}
$$

where $d_{i t}$ is the ED-BN index, $\gamma_{i}$ is an individual specific effect and $v_{i t}$ is a contemporaneous shock for person $i$ at time $t$. In what follows we cluster the standard errors by individual in all regression results to control for correlation across time due to individual component $\gamma_{i}$, as well as for any heteroskedasticity in $v_{i t}$.

One drawback of the regression model is that it ignores the large number of observations with an ED-BN index of zero. To address this we consider a Tobit model where the latent variable underlying the $\mathrm{ED}-\mathrm{BN}$ index is

$$
d_{i t}^{*}=\tilde{\beta}_{0}+\tilde{\beta}_{1} X_{i}+\tilde{\beta}_{2} A_{i t}+\tilde{\gamma}_{i}+\tilde{v}_{i t},
$$

and the observed value, $d_{i t}$, of the ED-BN index is

$$
d_{i t}=\left\{\begin{array}{c}
0 \text { if } d_{i t}^{*} \leq 0 \\
d_{i t}^{*} \text { otherwise }
\end{array}\right.
$$

We assume that $\tilde{\gamma}_{i}$ and $\tilde{v}_{i t}$ are independent and distributed as i.i.d. (over time and individuals)

as $N\left(0, \sigma_{\gamma}^{2}\right)$ and $N\left(0, \sigma_{v}^{2}\right)$ respectively. We again maximize the period by period Tobit likelihood function but adjust the standard errors to control for correlation across time due to the 
individual component $\gamma_{i}{ }^{28}$

One criticism of the above regression and Tobit models is that they treat the ED-BN index as a cardinal index. It may be more appropriate to treat this index as representing ordinal data such as, for example: $z_{i t}=0$ if the ED-BN index equals $0, z_{i t}=1$ if the index is in $[1,5]$, $z_{i t}=2$ if the index is in $[6,10]$, and $z_{i t}=3$ if the index is greater than 10 . Note that the Probit equation is consistent with this model, but to gain efficiency over the Probit model here we consider an Ordered Probit with unknown limit points. Our statistical model is

$$
z_{i t}^{*}=\delta_{0}+\delta_{1} X_{i}+\delta_{2} A_{i t}+\lambda_{i}+e_{i t}
$$

where

$$
z_{i t}=\left\{\begin{array}{c}
0 \text { if } z_{i t}^{*} \leq 0 \\
1 \text { if } 0<z_{i t}^{*} \leq \theta_{L 2} \\
2 \text { if } \theta_{L 2}<z_{i t}^{*} \leq \theta_{U 2} \\
3 \text { if } z_{i t}^{*}>\theta_{U 2} .
\end{array}\right.
$$

Note that this Ordered Probit model imposes less structure than the Tobit model. However, since we are also estimating the limit points $\theta_{L 2}$ and $\theta_{U 2}$, we cannot identify the variance of the composite error term $\lambda_{i}+e_{i t}$, and thus the Tobit and Ordered Probit coefficients are not comparable in terms of magnitude, but should have the same sign (and similar statistical significance).

\subsection{Results: The SES-BN Gradient when using the ED-BN Index}

The Regression, Tobit and Ordered Probit results are in Table 5, where the independent variables are the same as in Table 4 for the Probit models. The coefficients for the linear model and the partial effects for the Tobit model are very similar in terms of size and significance, so we discuss only the former. They show that the effect of being White, holding the other variables constant, is significantly negative. In terms of magnitude, being White lowers the ED-BN index by 0.24 , which is about a $20 \%$ reduction relative to the mean value (of 1.2 ), holding all else equal (in what follows we do not repeat the latter qualification). Further, the ED-BN index is significantly decreasing in age; each additional year of aging decreases the ED-BN index by

\footnotetext{
28 Since the Tobit model will be inconsistently estimated with heteroskedasticity clustering cannot be used to adjust for heteroskedasticity.
} 
about $11 \%$ of its mean value. ${ }^{29}$ Perhaps equally surprising as the results for African Americans, the index is also significantly decreasing in family income; being middle income lowers the index by about 0.38 (a $32 \%$ reduction relative to the mean) as compared to the lowest income group, while being in the highest income group lowers the index by about 0.49 (more than a $40 \%$ reduction relative to the mean) as compared to the lowest family income. Having the highest parental education significantly lowers the index by 0.31 (a $26 \%$ reduction of the mean value) as compared to those with the lowest parental education, while having parents with some college education lowers the ED-BN index by a (significant) 0.20. When we include year dummies (the lower panel of Table 5), only the coefficients for age are affected, and these coefficients are now estimated imprecisely. This latter result is not surprising since there is not much age variation at the start of the sample, so the girls tend to act like a single cohort. The Ordered Probit coefficients have the same sign, and the same level of significance, as in the Regression/Tobit models, indicating that the latter are not overly restrictive.

$<$ Insert Table 5 here $>$

\section{The Role of Personality Traits}

The NHLBIS contains rich information about personality indices capturing tendencies towards perfectionism, feelings of ineffectiveness, interpersonal distrust, and body dissatisfaction. As noted above, researchers have found a strong correlation between these personality characteristics and BN behavior. Here we investigate if race and income still play a role in the determination of $\mathrm{BN}$ once we control for these personality characteristics as a way of understanding the racial and class differences.

We again use regression and Tobit models for the ED-BN index. In the regression case, using an obvious change in notation our estimating equation becomes

$$
b_{i t}=\varphi_{0}+\varphi_{1} X_{i}+\varphi_{2} A_{i t}+\varphi_{3} p_{i t}+\omega_{i}+e_{i t},
$$

where $p_{i t}$ denotes the vector of personality indices (which change over time). The corresponding specification for the Tobit model is straightforward by now and we omit it for space considerations. Note if the estimates of $\varphi_{3}$ are statistically significant we cannot interpret these effects as causal, since individuals may have unobservables that affect both $b_{i t}$ and $p_{i t}$. At this point we simply consider whether adding them affects the size and significance of the SES coefficients as

\footnotetext{
29 We also estimated a specification that included quadratic effects in age. The estimates imply that going from age 12 to 14 (14 to 16) decreases the ED-BN index by $0.20(0.15)$.
} 
an attempt to understand the latter. The results obtained using this specification are reported in Table 6.

Note, however, that the personality traits may be correlated with $\omega_{i}$ if they are driven by time constant genetic factors, which may also affect $\mathrm{BN}$, leading to bias in the coefficients for $p_{i t}$ and for $X_{i} \cdot{ }^{30}$ If we address this endogeneity using fixed effects regressions or first-differencing, the time-constant SES variables will be eliminated. ${ }^{31}$ To allow for correlation of the personality traits with the unobserved effect while retaining the (exogenous) SES variables, we propose the following estimation approach. Taking deviations from individual means we have, ${ }^{32}$

$$
\left(b_{i t}-\bar{b}_{i}\right)=\varphi_{2}\left(A_{i t}-\bar{A}_{i}\right)+\varphi_{3}\left(p_{i t}-\bar{p}_{i}\right)+e_{i t}
$$

As usual the time constant SES variables drop out, but if we treat them as independent of $\omega_{i}$ we can estimate their coefficients once we have estimated $\varphi_{2}$ and $\varphi_{3}$. To do so we form the residuals,

$$
\epsilon_{i t}=b_{i t}-\hat{\varphi}_{2} A_{i t}-\hat{\varphi}_{3} p_{i t}
$$

and then run the regression,

$$
\overline{\epsilon_{i}}=\varphi_{0}+\varphi_{1} X_{i}+e_{i}
$$

where $\bar{\epsilon}$ is the individual mean of $\epsilon_{i t}$. Estimating $\varphi_{1}$ this way is a modification of Hausman and Taylor (1981), and we follow their paper to get the appropriate standard errors for our estimate of $\varphi_{1} \cdot{ }^{33}$ The results obtained using this specification are reported in Table 7.

The fixed-effects Tobit model is not a natural extension of the fixed effect linear regression model, so we briefly discuss the estimation of the former. In an obvious change of notation the latent variable is

$$
b_{i t}^{*}=\varphi_{0}+\varphi_{1} X_{i}+\varphi_{2} A_{i t}+\varphi_{3} p_{i t}+\omega_{i}+e_{i t},
$$

${ }^{30}$ If the personality indices are independent of $X_{i}$ there will not be any bias in the coefficients of the SES variables, but in this case there is no need to control for the personality characteristics.

31 We present estimates of the parameters of first-differenced equation in Appendix B Table B.2. The results we obtained are similar to those from the level estimates (in terms of the magnitude and significance of the coefficients on the personality indices).

32 To use this form of the fixed effect model we need to assume strict exogeneity (see Wooldridge 2002, pp 325-328). That is $e_{i s}$ (for all time periods $s$ ) is independent of $p_{i t}$ and $X_{i}$. A first differenced version of the equation does not require this assumption. The results we obtained are quite similar to those from the level estimates we report (in terms of the magnitude and significance of the coefficients on the personality indices) and are available upon request.

33 Note that the estimates of the coefficients for the personality characteristics are not affected by whether or not we assume the SES variables are independent of $\omega_{i}$. 
and the observed value is

$$
b_{i t}=\left\{\begin{array}{c}
0 \text { if } b_{i t}^{*} \leq 0 \\
b_{i t}^{*} \text { otherwise. }
\end{array} .\right.
$$

We use Wooldridge's (2005) version of Chamberlain's (1984) correlated random effects approach by writing

$$
\omega_{i}=\delta_{0}+\delta_{1} \bar{X}_{i}+\delta_{2} \bar{A}_{i}+\delta_{3} \bar{p}_{i}=\delta_{0}+\delta_{1} X_{i}+\delta_{2} \bar{A}_{i}+\delta_{3} \bar{p}_{i}
$$

where $\bar{A}_{i}$ and $\bar{p}_{i}$ represent the individual means for age and the vector of the personality characteristics. Our index function now becomes

$$
b_{i t}^{*}=\left(\varphi_{0}+\delta_{0}\right)+\left(\varphi_{1}+\delta_{1}\right) X_{i}+\delta_{2} \bar{A}_{i}+\varphi_{2} A_{i t}+\varphi_{3} p_{i t}+\delta_{3} \bar{p}_{i}+e_{i t} .
$$

As usual, the coefficients $\varphi_{1}$ on the SES characteristics are not identified unless we assume that they are independent of $\omega_{i}$, i.e., $\delta_{1}=0$. Note again that the estimates of the coefficients for the personality characteristics are not affected by whether we assume the SES variables are independent of $\omega_{i}$. We report the estimates in Appendix B, Table B.2.

\subsection{Results: Do Personality Traits Account for Disparities?}

Table 6 contains the results for the linear and Tobit models where personality indices are included as explanatory variables and fixed effects are not included. Column (1) presents the regression results with the distrust, ineffectiveness and perfectionism indices (but not the body dissatisfaction index) used as explanatory variables, while in column (2) we also include the body dissatisfaction index. ${ }^{34}$ Note first that race, age and family income, but not parental education, are still statistically significant when we condition on personality indices (independent of which ones we condition on), although the size of the income differentials, but not the race differential, is reduced. Second, the ineffectiveness, perfectionism and body dissatisfaction indices, but not the distrust index, are significantly associated with the ED-BN index in the direction expected.

Since the personality indices and the ED-BN are (almost) continuous variables, it is perhaps most illuminating to consider elasticities measured at the mean values of these variables (see Table 1). Using the estimates in column (2), we find large elasticities of the ED-BN index with respect to the ineffectiveness, perfectionism, and body dissatisfaction indices, which are 0.56 , 0.68 , and 0.25 , respectively. Alternatively, a (separate) five point increase in the ineffectiveness

\footnotetext{
${ }^{34}$ We present results with and without the body dissatisfaction index as a regressor, since body dissatisfaction is more likely to be affected by BN behavior.
} 
index and perfectionism index each increase the ED-BN index by about 1.3 and 0.7 respectively, while a (separate) five point increase in the body dissatisfaction index increases the ED-BN index by about 0.2 . Note that each of these estimated coefficients is substantial when compared to the mean ED-BN index of 1.2. Column (5) contains the Tobit partial effects when we include the personality traits as explanatory variables. The results are close to those from the linear model. Each of the SES variables continue to be strongly related to BN behavior when we condition on personality indices. ${ }^{35}$

\section{$<$ Insert Table 6 here $>$}

In column (3) we use race-income interactions while controlling for all personality indices and education in the linear model; the corresponding estimates for the Tobit model is in column (6). The results confirm that low and middle income African Americans have the strongest tendency towards bulimic behavior. ${ }^{36}$ However, among Whites, low income girls have a substantially higher propensity toward BN than both middle and high income girls. Further, middle (high) income Whites present an ED-BN index that is $49 \%$ (36\%) lower than low income African Americans. Finally, among the lowest income White households, the ED-BN index drops by about $25 \%$ if one moves from the lowest income family to a middle income family (that is, a $25 \%$ decrease relative to the mean ED-BN index).

In columns (4) and (7) we report the linear and Tobit estimates with race-education interactions conditional on family income and all personality indices. ${ }^{37}$ While all whites have significantly lower ED-BN indices than all African Americans, and the disparity slightly increases with parental education, within the Whites parental education does not play a remarkable role.

Table 7 presents estimates that allow the personality indices are not independent of the individual effect. The first specification concerns the case when there are no interactions between the SES variables. Further, the personality indices continue to be statistically significant, indicating that the coefficients reported in Table 6 do not simply arise from a correlation between them and the individual effect. From specification 2 (with interactions) we find, once again, that lower and middle income African American girls, and lower income White girls experience higher ED-BN behavior. Finally, specification 3 shows that the ED-BN index is significantly decreasing for White girls as the education level of the parents increases, and is significantly

\footnotetext{
35 For a discussion of why personality traits can be considered exogenous with respect to unobserved individual-specific heterogeneity see the discussion in Appendix B.

36 Specifically, among African Americans, girls from high income households score an average of 34 percentage points lower on the ED-BN index than girls from low income families. (All percentages are relative to the ED-BN mean.) Here the base case is African Americans from the lowest income households.

37 The base case is African Americans from the lowest educated families.
} 
lower than African-American girls. Note that the coefficients on the race and income variables become larger and more significant in columns (1) and (2), relative to those in Table 6, and continue to indicate that ED-BN behavior is significantly higher for African American and low income girls. ${ }^{38}$

As a robustness check, we estimate the Tobit partial effects, when we allow $p_{i t}$ and $\omega_{i}$ to be correlated, using the correlated random effects approach of Chamberlain (1984)/Wooldridge (2005). We find that these results are very similar to those from the linear model. These are presented in Appendix B for expositional ease.

\section{$<$ Insert Table 7 here $>$}

In sum, our empirical findings reveal strong disparities in the bulimic patterns across SES groups that persist even when we condition on the personality characteristics. Moreover, our results are robust to different identifying assumptions and estimation methods (including both linear and non linear models).

\section{Conclusions}

This study grew out of the widespread perception that EDs are over-represented in the White upper socioeconomic groups. The belief that EDs are limited to White women prevails despite the contradicting evidence presented in a few epidemiological studies (see Wade et al., 2011). As noted by Gordon, et al. (2001), this belief can impair peoples judgments such that ED symptoms in ethnic minorities may be overlooked, and strengthen racial stereotypes about EDs. $^{39}$ We provide new insights into the crucial roles that race, family income, and parental education attainment play: African Americans are more likely to exhibit bulimic behavior. In addition, the incidence of $\mathrm{BN}$ is decreasing in income and in parental education. These results stand in stark contrast to the popular conceptions about who suffers from BN. We present evidence showing that popular conception is based on who is diagnosed with an ED rather than who exhibits bulimic behavior. Thus a primary reason for the disparity between diagnosis and behavior occurs because White teenage girls are more likely to be diagnosed with an ED conditional on having it.

\footnotetext{
38 In terms of magnitude, being White lowers the ED-BN index by 0.30 , which is about a $25 \%$ reduction relative to the mean value (of 1.2). The index is also significantly decreasing in family income; being middle income lowers the index on average by about $25 \%$ as compared to the lowest income group, while being in the highest income group results on average in a reduction of $28 \%$ as compared to the lowest family income.

39 In fact, they find that participants in their study were more prone to recognize ED symptoms when they read about a White woman than when they read about an African American or Hispanic woman.
} 
Our paper suggests that when a diagnosis is based on an underlying index, using all the information contained in the index, in addition to the zero-one diagnosis, can be very helpful to obtain precise parameter estimates. Using information on the index itself, rather than only information on the incidence of $\mathrm{BN}$, dramatically increases the precision of our results but does not change the coefficients qualitatively. However, given that the index is based on questions concerning both bingeing and purging behaviors, there is the danger that the index mainly captures overeating behavior. This concern is eliminated by noting that there is essentially no correlation between the ED-BN index and BMI, where the latter is commonly used to measure the degree of obesity.

Our findings show the usefulness of using appropriate econometric techniques for investigating public health issues from survey data and are robust to different estimation methods and identifying assumptions. Our results have important policy implications; specifically, they indicate substantial outreach should be directed to low income girls, girls from low-education households, and especially to African Americans. It seems clear that the Affordable Care Act (Obamacare) will make paying for the treatment of EDs for low and middle income families much easier than it was via Medicaid or private insurance in the 1990s, so these disparities may diminish over time. However, if the disparities in diagnosis are a result of disparities in who is seen as likely to experience an ED, the disparities will remain without a significant expansion in outreach to underserved communities. 
Table 1: NHLBIS Descriptive Statistics

\begin{tabular}{lcccc}
\hline & Mean & $\begin{array}{c}\text { Standard } \\
\text { Deviation }\end{array}$ & $\begin{array}{c}\text { Clustered Standard } \\
\text { Error of Mean }\end{array}$ & $\begin{array}{c}\text { Number of } \\
\text { Waves }\end{array}$ \\
\hline ED-BN Index & 1.279 & 2.682 & 0.039 & $3,5,7,9,10$ \\
Bulimia Nervosa & 0.022 & 0.145 & 0.002 & $3,5,7,9,10$ \\
Age & 14.360 & 2.991 & 0.014 & All 10 \\
White & 0.480 & 0.499 & 0.01 & 1 \\
Parents High School or Less & 0.255 & 0.436 & 0.009 & 1 \\
Parents Some College & 0.393 & 0.488 & 0.01 & 1 \\
Parents Bachelor Degree or More & 0.352 & 0.477 & 0.01 & 1 \\
Income less than $\$ 20,000$ & 0.318 & 0.466 & 0.01 & 1 \\
Income in [\$20000, \$40000] & 0.315 & 0.465 & 0.01 & 1 \\
Income more than \$40,000 & 0.367 & 0.482 & 0.01 & $3,5,7,9,10$ \\
Body Dissatisfaction Index* & 8.039 & 7.554 & 0.131 & $3,5,9,10$ \\
Distrust Index** & 3.589 & 3.492 & 0.056 & $3,5,9,10$ \\
Ineffectiveness Index*** & 2.752 & 3.915 & 0.063 & $3,5,9,10$ \\
Perfectionism Index**** & 6.468 & 3.290 & 0.052 & 1 \\
\hline
\end{tabular}

Notes: Income is in 1988\$; * ranges from 0 to 27 (maximal dissatisfaction); ** ranges from 0 to 21 (maximal distrust); *** ranges from 0 to 29 (maximal ineffectiveness); **** ranges from 0 to 18 (maximal perfectionism). See Appendix

A for more detailed description of the variables. Bulimia is defined as an ED-BN Index score greater than 10. 
Table 2: Distribution of the ED-BN Index by Characteristics in the NHLBIS Sample

\begin{tabular}{lcccc}
\multicolumn{1}{c}{ Variable } & \multicolumn{5}{c}{ ED-BN Index } \\
& 0 & {$[1,5]$} & {$[6,10]$} & $>10$ (Bulimia Nervosa) \\
& 66.57 & 26.21 & 5.06 & 2.16 \\
\hline Overall & 70.35 & 24.02 & 3.91 & 1.72 \\
White & 63.07 & 28.24 & 6.13 & 2.54 \\
African American & 62.26 & 27.88 & 6.57 & 3.29 \\
Parents High School or Less & 65.27 & 27.31 & 5.38 & 2.03 \\
Parents Some College & 70.99 & 23.84 & 3.65 & 1.52 \\
Parents Bachelor Degree or More & & & & \\
Household Income (in 1988\$): & & & & \\
Income less than $\$ 20,000$ & 59.96 & 29.78 & 6.93 & 3.33 \\
Income in [\$20000, \$40000] & 68.35 & 25.1 & 4.41 & 2.14 \\
Income more than \$40,000 & 70.67 & 24.08 & 3.97 & 1.28 \\
\hline
\end{tabular}


Table 3: Distribution of the Diagnosed Eating Disorder by Characteristics

\begin{tabular}{|c|c|c|c|c|c|c|c|c|}
\hline & \multicolumn{4}{|c|}{$\begin{array}{l}\text { Add Health Black and White } \\
\text { Diagnosed with an ED }\end{array}$} & \multicolumn{4}{|c|}{$\begin{array}{c}\text { Add Health Black and White Urban } \\
\text { Diagnosed with an ED }\end{array}$} \\
\hline & \multicolumn{2}{|c|}{ Yes } & \multicolumn{2}{|c|}{ No } & \multicolumn{2}{|c|}{ Yes } & \multicolumn{2}{|c|}{ No } \\
\hline & Mean & Std Dev & Mean & Std Dev & Mean & Std Dev & Mean & Std Dev \\
\hline Overall & 0.036 & 0.187 & & & 0.034 & 0.187 & & \\
\hline Age & 20.596 & 1.182 & 20.651 & 1.130 & 20.677 & 1.156 & 20.714 & 1.130 \\
\hline White & 0.904 & 0.295 & 0.721 & 0.449 & 0.871 & 0.338 & 0.662 & 0.473 \\
\hline Parents High School or Less & 0.360 & 0.482 & 0.404 & 0.491 & 0.339 & 0.477 & 0.385 & 0.487 \\
\hline Parents Some College & 0.147 & 0.355 & 0.190 & 0.392 & 0.145 & 0.355 & 0.194 & 0.395 \\
\hline Parents Bachelor Degree or More & 0.493 & 0.502 & 0.406 & 0.491 & 0.516 & 0.504 & 0.421 & 0.494 \\
\hline \multicolumn{9}{|l|}{ Household Income: } \\
\hline Income less than $\$ 20,000$ & 0.243 & 0.430 & 0.255 & 0.436 & 0.242 & 0.432 & 0.266 & 0.442 \\
\hline Income in $[\$ 20000, \$ 40000]$ & 0.213 & 0.411 & 0.301 & 0.459 & 0.242 & 0.432 & 0.286 & 0.452 \\
\hline Income more than $\$ 40,000$ & 0.544 & 0.500 & 0.444 & 0.497 & 0.516 & 0.504 & 0.448 & 0.497 \\
\hline
\end{tabular}

Note: Income is in 1988\$ 


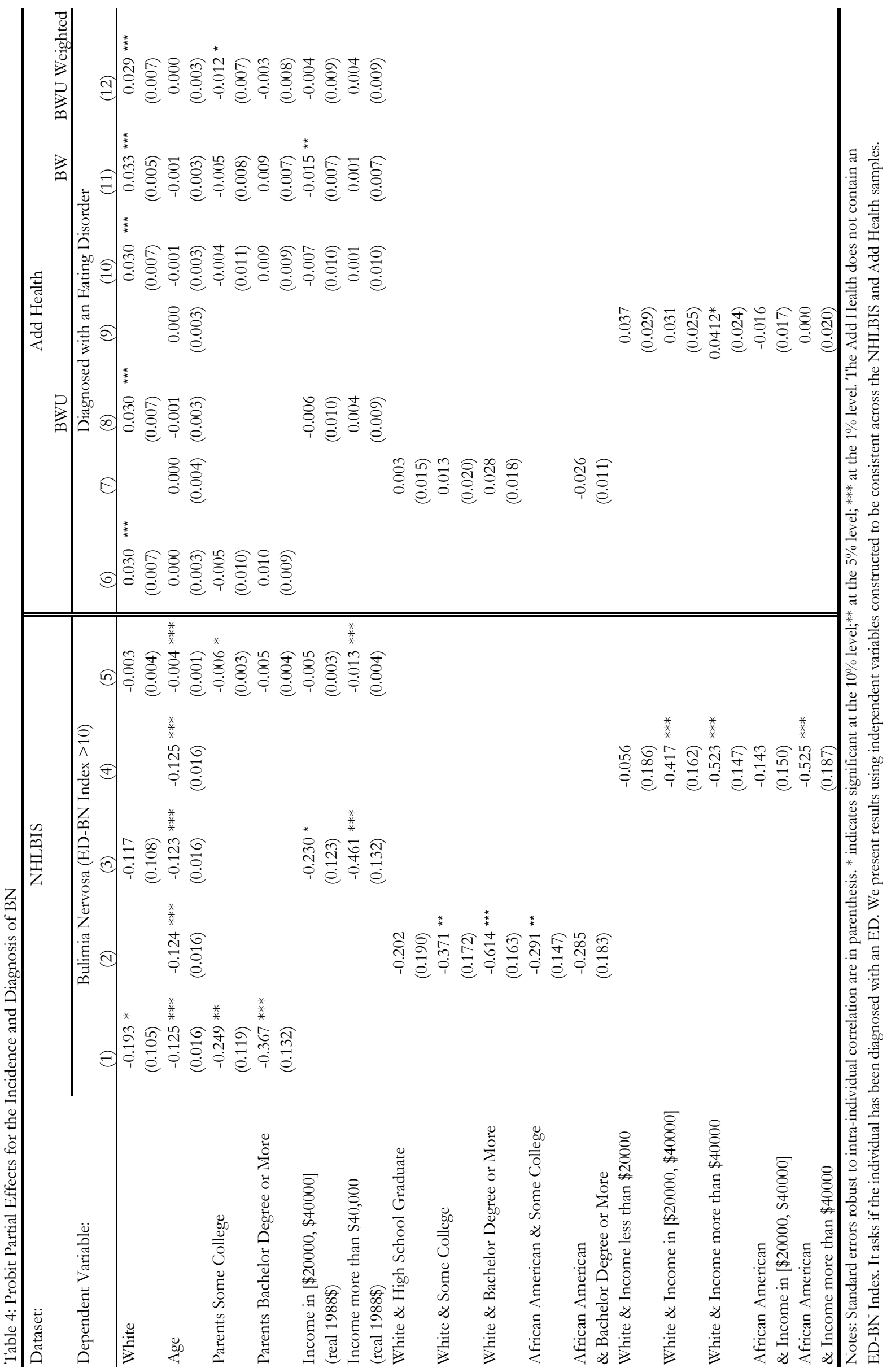


Table 5: Comparison of Coefficients from Linear, Tobit and

Ordered Probit Models

\begin{tabular}{|c|c|c|c|}
\hline & \multicolumn{3}{|c|}{ ED-BN Index } \\
\hline & $\begin{array}{l}\text { Linear } \\
\text { Model }\end{array}$ & Tobit & $\begin{array}{c}\text { Ordered } \\
\text { Probit }\end{array}$ \\
\hline White & $\begin{array}{l}-0.243^{* * *} \\
(0.088)\end{array}$ & $\begin{array}{l}-0.676^{* * *} \\
(0.240)\end{array}$ & $\begin{array}{l}-0.108^{* * *} \\
(0.041)\end{array}$ \\
\hline Age & $\begin{array}{l}-0.132^{* * *} \\
(0.011)\end{array}$ & $\begin{array}{l}-0.318^{* * *} \\
(0.029)\end{array}$ & $\begin{array}{l}-0.051 * * * \\
(0.005)\end{array}$ \\
\hline Parents Some College & $\begin{array}{l}-0.198^{*} \\
(0.113)\end{array}$ & $\begin{array}{l}-0.321 \\
(0.280)\end{array}$ & $\begin{array}{l}-0.042 \\
(0.047)\end{array}$ \\
\hline $\begin{array}{l}\text { Parents Bachelor Degree } \\
\text { or More }\end{array}$ & $\begin{array}{l}-0.313^{* * *} \\
(0.116)\end{array}$ & $\begin{array}{l}-0.703^{* *} \\
(0.316)\end{array}$ & $\begin{array}{l}-0.100^{*} \\
(0.053)\end{array}$ \\
\hline Income in $[\$ 20000, \$ 40000]$ & $\begin{array}{l}-0.377 * * * \\
(0.112)\end{array}$ & $\begin{array}{l}-1.029 * * * \\
(0.287)\end{array}$ & $\begin{array}{l}-0.174 * * * \\
(0.048)\end{array}$ \\
\hline Income more than $\$ 40,000$ & $\begin{array}{l}-0.488^{* * *} \\
(0.107)\end{array}$ & $\begin{array}{l}-1.278^{* * *} \\
(0.295)\end{array}$ & $\begin{array}{l}-0.209 * * * \\
(0.050)\end{array}$ \\
\hline Constant & $\begin{array}{l}3.975^{* * *} \\
(0.227)\end{array}$ & $\begin{array}{l}3.871 * * * \\
(0.518)\end{array}$ & \\
\hline Year Dummies Included & & & \\
\hline White & $\begin{array}{l}-0.227 * * * \\
(0.088)\end{array}$ & $\begin{array}{l}-0.629 * * * \\
(0.240)\end{array}$ & $\begin{array}{l}-0.100 * * \\
(0.041)\end{array}$ \\
\hline Age & $\begin{array}{l}0.010 \\
(0.060)\end{array}$ & $\begin{array}{l}0.122 \\
(0.174)\end{array}$ & $\begin{array}{l}0.024 \\
(0.030)\end{array}$ \\
\hline Parents Some College & $\begin{array}{l}-0.193^{*} \\
(0.113)\end{array}$ & $\begin{array}{l}-0.311 \\
(0.279)\end{array}$ & $\begin{array}{l}-0.040 \\
(0.047)\end{array}$ \\
\hline $\begin{array}{l}\text { Parents Bachelor Degree } \\
\text { or More }\end{array}$ & $\begin{array}{l}-0.299 * * * \\
(0.116)\end{array}$ & $\begin{array}{l}-0.657^{* *} \\
(0.316)\end{array}$ & $\begin{array}{l}-0.093^{*} \\
(0.053)\end{array}$ \\
\hline Income in $[\$ 20000, \$ 40000]$ & $\begin{array}{l}-0.384 * * * \\
(0.112)\end{array}$ & $\begin{array}{l}-1.050^{* * *} \\
(0.286)\end{array}$ & $\begin{array}{l}-0.178^{* * *} \\
(0.048)\end{array}$ \\
\hline Income more than $\$ 40,000$ & $\begin{array}{l}-0.500^{* * *} \\
(0.106)\end{array}$ & $\begin{array}{l}-1.314 * * * \\
(0.294)\end{array}$ & $\begin{array}{l}-0.216^{* * *} \\
(0.050)\end{array}$ \\
\hline Constant & $\begin{array}{l}1.362 \\
(1.169)\end{array}$ & $\begin{array}{l}-4.348 \\
(3.355)\end{array}$ & \\
\hline Sample Size & 9591 & 9591 & 9591 \\
\hline
\end{tabular}


Table 6: Demographic Variables, Personality Indices and the ED-BN Index

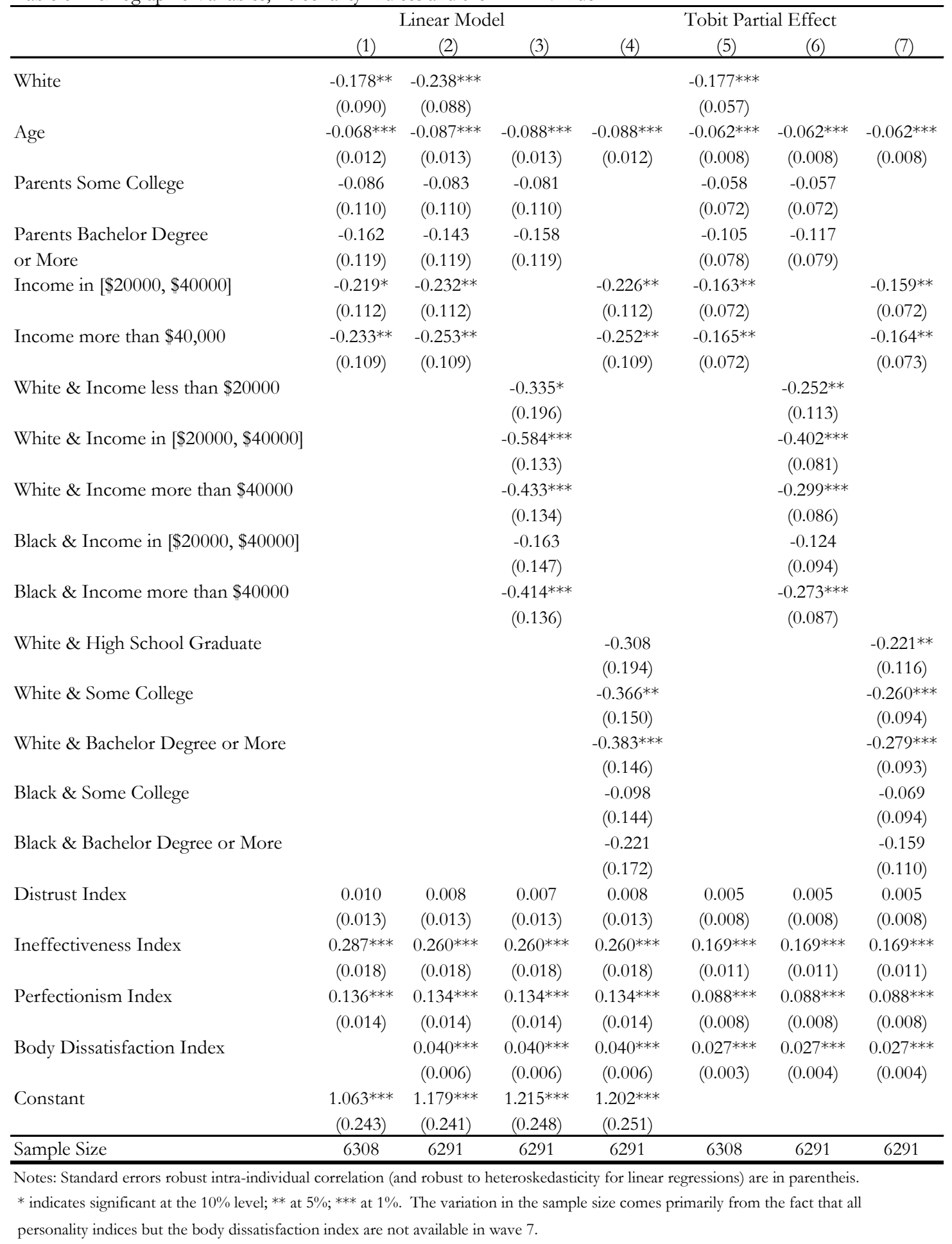


Table 7: ED-BN Index Estimates with Correlated Individual Effects

\begin{tabular}{|c|c|c|c|c|c|c|}
\hline & \multicolumn{2}{|c|}{ Specification 1} & \multicolumn{2}{|c|}{ Specification 2} & \multicolumn{2}{|c|}{ Specification 3} \\
\hline & Estimate & Std. Err. & Estimate & Std. Err. & Estimate & Std. Err. \\
\hline White & $-0.304 * * *$ & (0.093) & & & & \\
\hline Age & $-0.114 * * *$ & $(0.011)$ & $-0.115 * * *$ & $(0.011)$ & $-0.114 * * *$ & $(0.011)$ \\
\hline \multicolumn{7}{|l|}{ Parent's Education and Interactions } \\
\hline Some College & -0.121 & $(0.109)$ & -0.120 & $(0.109)$ & & \\
\hline Bachelor Degree or More & -0.198 & $(0.126)$ & $-0.214 *$ & $(0.126)$ & & \\
\hline White \& High School Graduate & & & & & $-0.358 * *$ & (0.177) \\
\hline White \& Some College & & & & & $-0.462 * * *$ & $(0.162)$ \\
\hline White \& Bachelor Degree or More & & & & & $-0.502 * * *$ & $(0.158)$ \\
\hline Black \& Some College & & & & & -0.134 & $(0.137)$ \\
\hline Black \& Bachelor Degree or More & & & & & -0.264 & $(0.173)$ \\
\hline \multicolumn{7}{|l|}{ Income and Interactions } \\
\hline Income in $[\$ 20000, \$ 40000]$ & $-0.295 * * *$ & (0.111) & & & $-0.290 * * *$ & $(0.111)$ \\
\hline Income more than $\$ 40,000$ & $-0.340 * * *$ & $(0.121)$ & & & $-0.339 * * *$ & $(0.121)$ \\
\hline White \& Income less than $\$ 20000$ & & & $-0.405 * *$ & $(0.175)$ & & \\
\hline White \& Income in $[\$ 20000, \$ 40000]$ & & & $-0.712 * * *$ & $(0.143)$ & & \\
\hline White \& Income more than $\$ 40000$ & & & $-0.579 * * *$ & $(0.140)$ & & \\
\hline Black \& Income in $[\$ 20000, \$ 40000]$ & & & -0.224 & $(0.137)$ & & \\
\hline Black \& Income more than $\$ 40000$ & & & $-0.512 * * *$ & $(0.152)$ & & \\
\hline Time Varying Endogenous Variables & & & & & & \\
\hline Distrust Index & $-0.036 * * *$ & $(0.013)$ & $-0.036 * * *$ & $(0.013)$ & $-0.036 * * *$ & $(0.013)$ \\
\hline Ineffectiveness Index & $0.212 * * *$ & $(0.012)$ & $0.212 * * *$ & $(0.012)$ & $0.212 * * *$ & $(0.012)$ \\
\hline Perfectionism Index & $0.133 * * *$ & $(0.012)$ & $0.133 * * *$ & $(0.012)$ & $0.133 * * *$ & $(0.012)$ \\
\hline Body Dissatisfaction Index & $0.044 * * *$ & $(0.007)$ & $0.044 * * *$ & $(0.007)$ & $0.044 * * *$ & $(0.007)$ \\
\hline Constant & $1.976 * * *$ & $(0.221)$ & $2.002 * * *$ & $(0.224)$ & $1.995 * * *$ & $(0.220)$ \\
\hline Sample Size & 6291 & & 6291 & & 6291 & \\
\hline
\end{tabular}

Notes: Standard errors robust to intra-individual correlation are in parenthesis. $*$ indicates significant at the $10 \%$ level; $* *$ at $5 \%$; *** at $1 \%$. 


\section{Appendix}

\section{A Data Variable Definitions}

We describe the construction of the ED-BN index in the main text of the paper. The body dissatisfaction index is based on subject responses to nine items: 1) I think that my stomach is too big, 2) I think that my thighs are too large, 3) I think that my stomach is just the right size, 4) I feel satisfied with the shape of my body, 5) I like the shape of my buttocks, 6) I think my hips are too big, 7) I think that my thighs are just the right size, 8) I think that my buttocks are too large, 9) I think my hips are just the right size. This index ranges from 0 to 27, and responses are scored such that a higher score indicates more dissatisfaction. ${ }^{40}$

The perfectionism index is based on subject responses to six items: 1) In my family everyone has to do things like a superstar; 2) I try very hard to do what my parents and teachers want; 3) I hate being less than best at things; 4) My parents expect me to be the best; 5) I have to do things perfectly or not to do them at all; 6) I want to do very well. The subjects are offered the same responses, and the responses are scored in the same way as the ED-BN index.

The distrust index is based on subject responses to seven items: 1) I tell people about my feelings; 2) I trust people; 3) I can talk to other people easily; 4) I have close friends; 5) I have trouble telling other people how I feel; 6) I don't want people to get to know me very well; and 7) I can talk about my private thoughts or feelings. The scoring rule is as follows: "always" $=1$, "usually" $=2$, "often" $=3$, "sometimes" $=4$, "rarely" $=5$, and "never" $=6$ in questions 5 and 6 ; and "always" $=6$, "usually" $=5$, "often" $=4$, "sometimes" $=3$, "rarely" $=2$, and "never" $=1$ in questions $1,2,3,4$, and 7 . A response of 4-6 on a given question contributes zero points to the distrust index; a response of 3 contributes 1 point; a response of 2 contributes 2 points; and a response of 1 contributes 3 points. The distrust index is a sum of all contributing points.

The ineffectiveness index is based on subject responses to ten items: 1) I feel I can't do things very well; 2) I feel very alone; 3) I feel I can't handle things in my life; 4) I wish I were someone else; 5) I don't think I am as good as other kids; 6) I feel good about myself; 7) I don't like myself very much; 8) I feel I can do whatever I try to do; 9) I feel I am a good person; 10) I feel empty inside. The scoring rule is as follows: "always" $=1$, "usually" $=2$, "often" $=3$, "sometimes" $=4$, "rarely" $=5$, and "never" $=6$ in questions $1,2,3,4,5,7$, and 10; and "always" $=6$,

\footnotetext{
40 The scoring rule is as follows: "always" $=6$, "usually" $=5$, "often" $=4$, "sometimes" $=3$, "rarely" =2, and "never" $=1$ in questions $3,4,5,7$, and 9 and "always" $=1$, "usually" $=2$, "often" $=3$, "sometimes" $=4$, "rarely" =5, and "never" $=6$ in questions 1, 2, 6, and 8. Again a response of 4-6 on a given question contributes zero points to the body image index; a response of 3 contributes 1 point; a response of 2 contributes 2 points; and a response of 1 contributes 3 points. The body image index is the sum of the contributing points.
} 
"usually" =5, "often" =4, "sometimes" =3, "rarely" =2, and "never" $=1$ in questions 6,8, and 9 . A response of 4-6 on a given question contributes zero points to the ineffectiveness index; a response of 3 contributes 1 point; a response of 2 contributes 2 points; and a response of 1 contributes 3 points. The ineffectiveness index is a sum of all contributing points.

Table A.1 provides more details on the variables used from both datasets.

Table A.1: Variable Definitions

\begin{tabular}{|c|c|c|c|}
\hline Variable & Description & Coding & Dataset \\
\hline ED-BN Index & Eating Disorders Bulimia Subscale & Categorical Variable; Range $0-21$ & NHLBI \\
\hline Clinical Bulimia & Case of Clinical Bulimia & $=1$ if ED-BN Index $>10 ;=0$ Otherwise & NHLBI \\
\hline Diagnosed & Diagnosed with an Eating Disorder & $=1$ if Diagnosed; 0 Otherwise & ADD Health \\
\hline Body Dissatisfaction Index & Measures Poor Body Image Concerns & Categorical Variable; Range 0-27 & NHLBI \\
\hline Perfectionism Index & Measures Driveness for Perfection & Categorical Variable; Range $0-18$ & NHLBI \\
\hline Ineffectiveness Index & Measures Feelings of Ineffectiveness & Categorical Variable; Range 0-29 & NHLBI \\
\hline Distrust Index & Measures Interpersonal Distrust & Categorical Variable; Range $0-21$ & NHLBI \\
\hline Age & Respondent Age & & Both \\
\hline White & Respondent Race is White & $=1$ if Race is White; $=0$ if African American & Both \\
\hline Parents Some College & Highest Education of Parents & Dummy Variable Highest Education Some College & Both \\
\hline Parents Bachelor Degree or More & Highest Education of Parents & Dummy Variable Highest Education College Degree or More & Both \\
\hline Income less than $\$ 20,000$ & Household income (in 1988\$) & Dummy Variable Household Income is Less than $\$ 20,000$ & Both \\
\hline Income in $[\$ 20000, \$ 40000]$ & Household income (in 1988\$) & Dummy Variable Household Income is in Range $[\$ 20,000, \$ 40,000]$ & Both \\
\hline Income more than $\$ 40,000$ & Household income (in 1988\$) & Dummy Variable Household Income is Higher than $\$ 40,000$ & Both \\
\hline
\end{tabular}

\section{B Additional Specifications}

\section{B.1 Bulimia Nervosa LPM and Probit Estimates}

For the LPM the dependent variable is $w_{i t}=0$ if the ED-BN index is less than or equal to 10 and $w_{i t}=1$ otherwise; we cluster the standard errors to allow for heteroskedasticity and correlation across time for a given individual. We estimate a Probit model by maximizing the quasi-likelihood and clustering the standard errors by individuals. The Probit partial effects and LPM results are given in Table B.1 and are relatively similar to each other. They also have the same signs as the Tobit results. However fewer estimated coefficients are statistically significant in the Probit and LPM, and those that are significant occur at lower confidence levels. The fact that we have substantially fewer significant coefficients in the Probit and LPM estimates is again expected, since they use much less information per person than the other methods. Indeed, our estimates illustrate the importance of not simply focusing on whether an individual has a clinical case of BN for understanding the determinants of this disorder.

Table B.1 reports the estimate of the SES- BN gradient when we also control for personality traits in the LPM and Probit models. To allow for fixed effects in the LPM we report the result of first differencing in column (3), while in column (7) we use the Chamberlain 
(1984)/Wooldridge (2005) (hereafter C/W) correlated random effects model to control for individual effects that are correlated with the personality indices in the Probit model. ${ }^{41}$

Table B.1: Partial Effects of Demographic Variables and Personality Indices on Clinical Bulimia

\begin{tabular}{|c|c|c|c|c|c|c|c|}
\hline & \multicolumn{4}{|c|}{ Linear Probability Estimates } & \multicolumn{3}{|c|}{ Probit Estimates } \\
\hline & $(1)$ & (2) & (3) & $(4)$ & $(5)$ & (6) & $(7)$ \\
\hline White & $\begin{array}{l}-0.004 \\
(0.005)\end{array}$ & $\begin{array}{l}-0.005 \\
(0.005)\end{array}$ & & & $\begin{array}{l}-0.0054^{*} \\
(0.0030)\end{array}$ & $\begin{array}{c}-0.0065^{* *} \\
(0.0027)\end{array}$ & \\
\hline Age & $\begin{array}{c}-0.002^{* * *} \\
(0.001)\end{array}$ & $\begin{array}{c}-0.003^{* * *} \\
(0.001)\end{array}$ & & & $\begin{array}{c}-0.0016^{* * *} \\
(0.0005)\end{array}$ & $\begin{array}{c}-0.0019 * * * \\
(0.0004)\end{array}$ & \\
\hline Parents Some College & $\begin{array}{l}-0.005 \\
(0.006)\end{array}$ & $\begin{array}{l}-0.005 \\
(0.006)\end{array}$ & & & $\begin{array}{l}-0.0030 \\
(0.0028)\end{array}$ & $\begin{array}{l}-0.0029 \\
(0.0026)\end{array}$ & \\
\hline $\begin{array}{l}\text { Parents Bachelor Degree } \\
\text { or More }\end{array}$ & $\begin{array}{l}-0.001 \\
(0.007)\end{array}$ & $\begin{array}{l}-0.000 \\
(0.007)\end{array}$ & & & $\begin{array}{l}-0.0010 \\
(0.0035)\end{array}$ & $\begin{array}{l}-0.0009 \\
(0.0033)\end{array}$ & \\
\hline Income in $[\$ 20000, \$ 40000]$ & $\begin{array}{l}-0.001 \\
(0.006)\end{array}$ & $\begin{array}{l}-0.001 \\
(0.006)\end{array}$ & & & $\begin{array}{l}-0.0001 \\
(0.0031)\end{array}$ & $\begin{array}{l}-0.0004 \\
(0.0029)\end{array}$ & \\
\hline Income more than $\$ 40,000$ & $\begin{array}{l}-0.008 \\
(0.006)\end{array}$ & $\begin{array}{l}-0.008 \\
(0.006)\end{array}$ & & & $\begin{array}{l}-0.0046 \\
(0.0032)\end{array}$ & $\begin{array}{l}-0.0047 \\
(0.0030)\end{array}$ & \\
\hline Distrust Index & $\begin{array}{l}-0.001 \\
(0.001)\end{array}$ & $\begin{array}{l}-0.001 \\
(0.001)\end{array}$ & $\begin{array}{l}-0.002 * \\
(0.001)\end{array}$ & $\begin{array}{c}-0.002^{* *} \\
(0.001)\end{array}$ & $\begin{array}{l}-0.0000 \\
(0.0003)\end{array}$ & $\begin{array}{l}-0.0000 \\
(0.0003)\end{array}$ & $\begin{array}{l}-0.0003 \\
(0.0002)\end{array}$ \\
\hline Ineffectiveness Index & $\begin{array}{c}0.010^{* * *} \\
(0.001)\end{array}$ & $\begin{array}{c}0.010^{* * *} \\
(0.001)\end{array}$ & $\begin{array}{c}0.009 * * * \\
(0.002)\end{array}$ & $\begin{array}{c}0.008^{* * *} \\
(0.001)\end{array}$ & $\begin{array}{c}0.0028^{* * *} \\
(0.0003)\end{array}$ & $\begin{array}{c}0.0023 * * * \\
(0.0003)\end{array}$ & $\begin{array}{c}0.0008^{* * *} \\
(0.0002)\end{array}$ \\
\hline Perfectionism Index & $\begin{array}{c}0.005^{* * *} \\
(0.001)\end{array}$ & $\begin{array}{c}0.005^{* * *} \\
(0.001)\end{array}$ & $\begin{array}{c}0.005^{* * *} \\
(0.002)\end{array}$ & $\begin{array}{c}0.004^{* * *} \\
(0.001)\end{array}$ & $\begin{array}{l}0.002^{* * *} \\
(0.0003)\end{array}$ & $\begin{array}{c}0.0018^{* * *} \\
(0.0003)\end{array}$ & $\begin{array}{c}0.0007 * * * \\
(0.0002)\end{array}$ \\
\hline Body Dissatisfaction Index & & $\begin{array}{l}0.001 * * \\
(0.000)\end{array}$ & $\begin{array}{l}0.002 * \\
(0.001)\end{array}$ & $\begin{array}{c}0.001 * * * \\
(0.000)\end{array}$ & & $\begin{array}{c}0.0006 * * * \\
(0.0001)\end{array}$ & $\begin{array}{c}0.0003^{* * *} \\
(0.0001)\end{array}$ \\
\hline Constant & $\begin{array}{c}0.008 \\
(0.014)\end{array}$ & $\begin{array}{c}0.011 \\
(0.014)\end{array}$ & $\begin{array}{l}-0.002 \\
(0.004)\end{array}$ & $\begin{array}{c}0.006 \\
(0.014)\end{array}$ & & & \\
\hline First Difference & No & No & Yes & No & NA & NA & NA \\
\hline $\begin{array}{l}\text { Chamberlain/Wooldridge } \\
\text { Fixed Effects }\end{array}$ & No & No & No & Yes & No & No & Yes \\
\hline Sample size & 6308 & 6291 & 2624 & 6291 & 6308 & 6291 & 6291 \\
\hline
\end{tabular}

See notes in Table 6.

\section{B.2 Correlated Random Effects Tobit Estimates}

We allow for the fact that in the Tobit model the personality traits may be driven by time constant genetic factors, which may also affect $\mathrm{BN}$, and use the $\mathrm{C} / \mathrm{W}$ correlated random effects

41 To control for the fixed effect, Chamberlain (1984) suggests making it a linear function of all values of the explanatory variables, while Wooldridge (2005) suggests making it the mean of the independent variables. We follow Wooldridge since it makes our estimates more comparable to the individual correlated effects regression estimates presented in Table 7. 
model. Specifically, for the Tobit model of equation (6) we assume that $\mu_{i}=\pi_{1} \bar{p}_{i}+u_{i}$ where $\bar{p}_{i}$ is the vector of means of the explanatory variables across time, $u_{i} \sim i i d N\left(0, \sigma_{u}^{2}\right)$. This yields

$$
y_{i t}^{*}=\varphi_{0}+\varphi_{1} X_{i}+\varphi_{2} p_{i t}+b_{t}+\pi_{1} \bar{p}_{i}+u_{i}+e_{i t} .
$$

We again maximize the quasi-likelihood and cluster the observations across individuals when calculating standard errors.

Table B.2: Effect of Demographic Variables and Personality Indices on the ED-BN Index

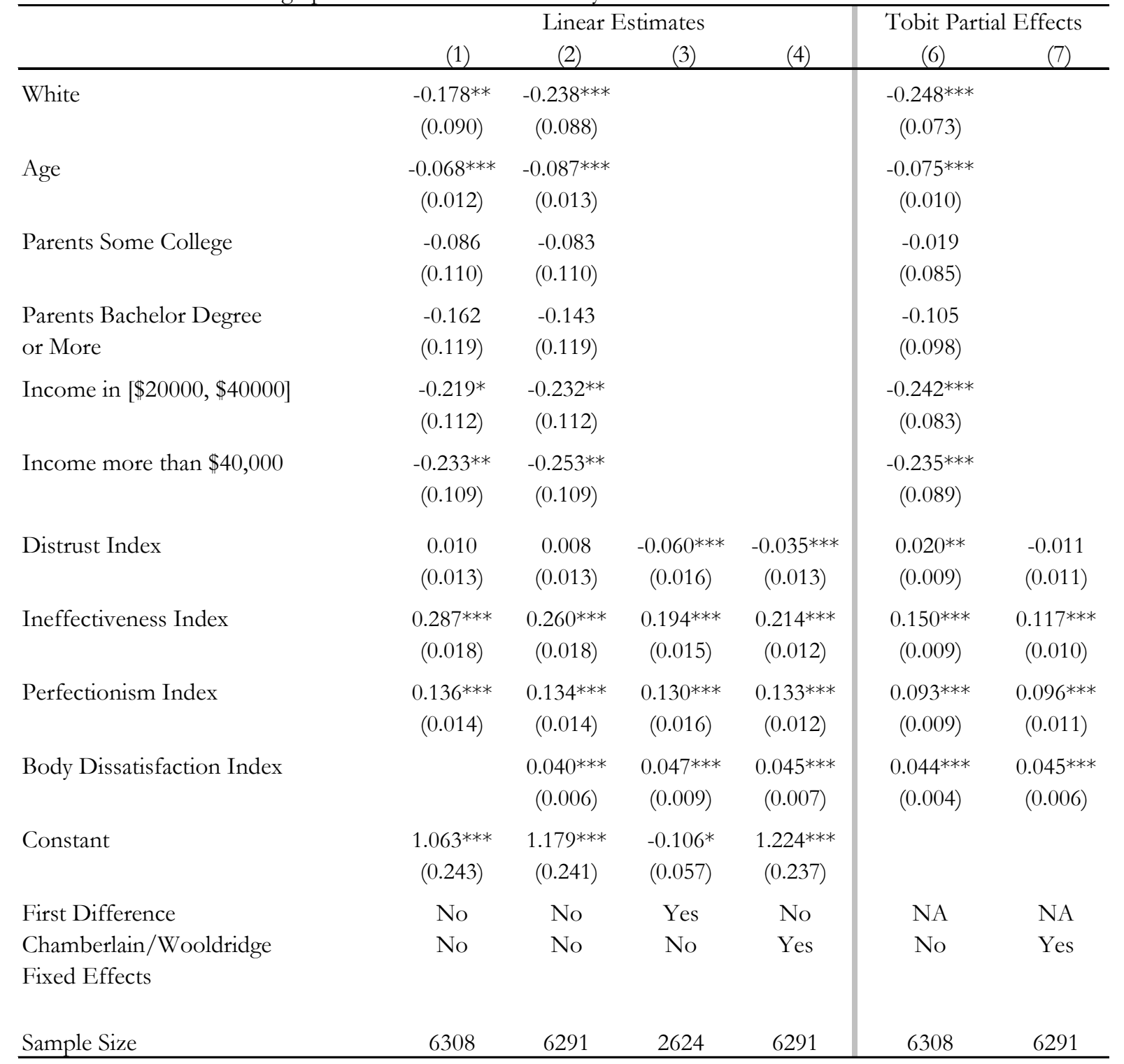

Notes: Standard errors robust intra-individual correlation (and robust to heteroskedasticity for linear regressions) are in parentheis. $*$ indicates significant at the $10 \%$ level; ${ }^{* *}$ at $5 \%$; *** at $1 \%$. The variation in the sample size comes primarily from the fact that all personality indices but the body dissatisfaction index are not available in wave 7 .

We present the estimates in Table B.2. To ease the comparison with the linear model, 
in Columns (1) and (2) we repeat the results reported in Columns (1) and (2) of Table 6. Column (3) reports the first difference estimates of the linear model, which will eliminate an unobserved genetic fixed effect that could potentially drive both the personality indices and the ED-BN index. These results are quite similar to those from the level estimates in terms of the magnitude and significance of the coefficients on the personality indices. ${ }^{42}$ In this case, the elasticities of the ED-BN index with respect to ineffectiveness, perfectionism, and body dissatisfaction indices are $0.42,0.66$, and 0.30 respectively. Note that these are very similar to what we found for the individual correlated effects model presented in Table 7, and also to those obtained when we do not allow for a fixed unobserved effect that could be causing a spurious correlation between the personality indices and ED-BN index. ${ }^{43}$ Since we need to use the more restrictive $\mathrm{C} / \mathrm{W}$ correlated random effects approach in the Tobit model, as a robustness check, column (4) presents the results of using this approach within the linear model. Note that the signs and significance of these estimates are reassuringly similar to the first difference estimates, suggesting that the Tobit estimates based on the $\mathrm{C} / \mathrm{W}$ approach are likely to be consistent.

Column (5) reports again the Tobit partial effect estimates of Column (4) in Table 6. Finally, we present the results of using the $\mathrm{C} / \mathrm{W}$ approach with the Tobit model in Column (6). Note that the Tobit partial effect estimates of perfectionism, body dissatisfaction and ineffectiveness are virtually identical in Columns (5) and (6). Each of the personality indices (except the one for distrust) continue to be strongly related to ED-BN behavior when we use the $\mathrm{C} / \mathrm{W}$ approach.

\footnotetext{
42 The only difference being that the coefficient on distrust is statistically significant and has an (unexpected) negative sign. Note that the distrust coefficient is significant and has the expected sign in the Tobit regression. Demographic variables are measured at the start of the survey and so drop out of the first differences.

${ }^{43}$ We cannot test the hypothesis difference in the estimates for the personality indices in columns (2) and (3) are different using the standard formula, since the estimates in column (2) are not fully efficient due to heteroskedasticity and intra-individual correlation. Rather, we would use a bootstrap approach to obtain a standard error for this difference. However, given how close the estimates for the personality indices are in (2) and (3), this step did not seem necessary.
} 


\section{References}

Adler, N. and D. Rehkopf (2008) "U.S. Disparities in Health: Descriptions, Causes, and Mechanisms," Annu. Rev. Public Health 29:235-52.

Alegria, M., M. Woo, and Z. Cao, et al. (2007) "Prevalence and Correlates of Eating Disorders in Latinos in the United States," International Journal of Eating Disorders 40, S15-S21.

American Psychiatric Association (APA) (1993) "Practice Guideline for Eating Disorders" American Journal of Psychiatry 150: 212-228.

American Psychiatric Association (APA) (2000) Diagnostic and Statistical Manual of Mental Disorders American Psychiatric Press: Washington DC. 4th Edition.

Becker, A.E., Arrindell, A., Striegel-Moore. R., et al. (2010), "A qualitative study of perceived social barriers to care for eating disorders: Perspectives from ethnically diverse health care consumers." International Journal of Eating Disorders 43(7):633-647.

Cavanaugh, C. and L. Ray (1999) "What we Know about Eating Disorders: Facts and Statistics" In Lemberg, Raymond and Cohn, Leigh (Eds) Eating Disorders: A Reference Sourcebook. Oryx. Press. Phoenix, AZ.

Chamberlain, G. (1984) "Panel Data," in Z. Griliches and M.D. Intriligator (eds.), Handbook of Econometrics, Volume 2. Amsterdam: North Holland, 1247-1318.

Currie, J. and R. Hyson (1999) "Is the Impact of Health Shocks Cushioned by Socioeconomic Status? The Case of Low Birth Weight," American Economic Review 19-22.

Cutler, D., E. Glaeser, and J. Shapiro (2003) "Why have Americans Become More Obese?" Journal of Economic Perspectives 17: 93-118.

Danielsdottir, S., D. Burgard, and W. Oliver-Pyatt (2009) "AED Guidelines for Childhood Obesity Prevention Programs," AED Position Statements URL: http: // www.aedweb.org /media/ Guidelines.cfm.

Department of Health and Human Services (2006) Agency for Healthcare Research and Quality, Management of Eating Disorders, Evidence Report/Technology Assessment, Number 135, 2006. AHRQ publication 06-E010. Senate Report accompanying the 2006 budget as reported by the Eating Disorders Coalition. URL: www.eatingdisorderscoalition.org.

Garner, D., P. Marion, M. Olmstead, and J. Polivy (1983) "Development and Validation of a Multidimensional Eating Disorder Inventory for Anorexia Nervosa and Bulimia," International Journal of Eating Disorders 2: 15-34.

Glewwe, P. and E. Miguel (2008) "The Impact of Child Health and Nutrition on Education in Less Developed Countries," Handbook of Development Economics Volume 4, (eds.) T. Paul Schultz and John Strauss, Elsevier. 
Gordon, K. M. Perez, and T. Joiner (2002) "The Impact of Racial Stereotypes on Eating Disorder Recognition," International Journal of Eating Disorders, 32(2):219-24.

Ham, J., D. Iorio, and M. Sovinsky (2013) "Caught in the Bulimic Trap? Persistence and State Dependence of Bulimia Among Young Women," Journal of Human Resources. 48(3):736-767.

Hausman, J.A. and W. Tayler (1981) "Panel Data and Unobservable Individual Effects," Econometrica 49(6), 1377-1398.

Hudson, J., E. Hiripi, H. Pope Jr, and R. Kesslre (2007) "The Prevalence and Correlates of Eating Disroders in the National Comorbidity Survey Replication," Biological Psychiatry 61: 348-358.

Keel, P., D. Dorer, D. Franko, S. Jackson, S., and D. Herzog (2005) "Postremission Predictors of Relapse in Women with Eating Disorders," American Journal of Psychiatry 162: 2263-2268.

Kempa, M. L. and A. J. Thomas (2007) "Culturally Sensitive Assessment and Treatment of Eating Disorders," Eating Disorders: The Journal of Treatment and Prevention, 8(1): 17-30.

Kemptner, D., H. Jürges, S. Reinhold (2011) "Changes in Compulsory Schooling and the Causal Effect of Education on Health: Evidence from Germany," Journal of Health Economics, forthcoming.

Khanam, R., H. S. Nghiem, L. B. Connelly (2009) "Child health and the income gradient: Evidence from Australia," Journal of Health Economics, 28: 805-817

Kimm, S., B. Barton, E. Obarzanek, et al. (2002) "Obesity Development During Adolescence in a Biracial Cohort: The NHLBI Growth and Health Study," Pediatrics 110: e54.

National Eating Disorders Association (2012) URL: http://www.nationaleatingdisorders.org/sites/default/files/ResourceHandouts/GeneralStatistics.pdf. Accessed Oct 29, 2013.

National Youth Risk Behavior Survey (2005) URL: http:// www.cdc.gov /HealthyYouth /yrbs/index.htm.

Nicdao, E.G., S. Hong, and D. Takeuchi, (2007) "Prevalence and Correlates of Eating Disorders among Asian Americans: Results from the National Latino and Asian American Study. International Journal of Eating Disorders, 40: S22-S26.

Philipson, T. and R. Posner (2008) "Is The Obesity Epidemic a Public Health. Problem? A Decade of Research on The Economics of Obesity," NBER Working Paper \#14010.

Reagan, P. and J. Hersch (2005) "Influence of Race, Gender, and Socioeconomic Status on Binge Eating Frequency in a Population-Based Sample," International Journal of Eating Disorders 38: 252-256. 
Rush, J., M. First, and D. Blacker (2008) Handbook of Psychiatric Measures American Psychiatric Publishing: Arlington, VA, 2nd Edition.

Society for Adolescent Medicine (2003) "Eating Disorders in Adolescents: Position Paper of the Society for Adolescent Medicine," Journal of Adolescent Health 33: 496-503.

Smith, J. (2007) "The Impact of Social Economic Status on Health over the Life Course," Journal of Human Resources 42(4): 739-764.

Striegel-Moore, R., G. Schreiber, A. Lo, P. Crawford, E. Obarzanek, and J. Rodin (2000) "Eating Disorder Symptoms in a Cohort of 11 to 16-Year-Old Black and White Girls: The NHLBI Growth and Health Study," International Journal of Eating Disorders 27:49-66.

Taylor, J., C. Caldwell, and R. Baser, et al. (2007) "Prevalence of Eating Disorders among Blacks in the National Survey of American Life. International Journal of Eating Disorders, 40, S10-S14.

Tenn, S., D. A. Herman, B. Wendling (2010) "The Role of Education in the Production of Health: An Empirical Analysis of Smoking Behavior," Journal of Health Economics 29: 404-417.

Thompson, O. (2011) "Racial Disparities in the Cognition-Health Relationship" Journal of Health Economics, 30(2):328-39

Wade, T. D., Keski-Rahkonen A., \& Hudson J. (2011). Epidemiology of eating disorders. In M. Tsuang and M. Tohen (Eds.), Textbook in Psychiatric Epidemiology (3rd ed.) (pp. 343-360). New York: Wiley.

Wooldridge, J. (2002) Econometric Analysis of Cross Section and Panel Data MIT Press.

Wooldridge, J. (2005), "Simple Solutions to the Initial Conditions Problem in Dynamic, Nonlinear Panel Data Models with Unobserved Effects," Journal of Applied Econometrics 20: 39-54. 